
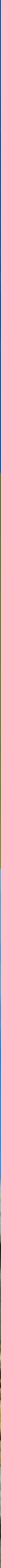


\section{Panta Rei \\ Revista Digital de Ciencia \\ y Didáctica de la Historia}

\section{6}

Revista anual

Fecha de inicio: 1995

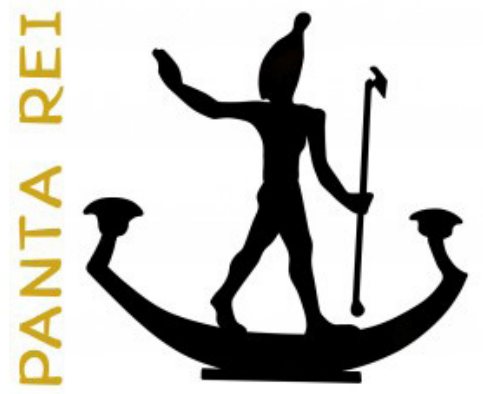

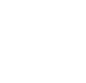




\section{CONSEJO DE REDACCIÓN}

\section{Coordinador editorial}

Egea Vivancos, Alejandro

[Didáctica de las Ciencias Sociales, UMU]

\section{Editores}

Botí Hernández, Juan Jesús

[CEPOAT, UMU]

Meseguer Gil, Antonio José

[CEPOAT, UNED]

Sáez Giménez, David Omar

[CEPOAT, UMU]

Sánchez Mondéjar, Celso Miguel

[CEPOAT, UMU]

\section{Secretaria}

Arias Ferrer, Laura

[Didáctica de las Ciencias Sociales, UMU]

\section{Responsable informático}

Martínez García, José Javier

[CEPOAT, UMU]

\section{Traducción y corrección lingüística}

Martínez Martínez, Cristina

[Sociedad Española de Lenguas Modernas]

Albaladejo Albaladejo, Sara

[ISEN, UMU]

\section{CONSEJO ASESOR}

Albero Muñoz, M. ${ }^{a}$ del Mar

[H. ${ }^{a}$ del Arte, UMU]

Chapman, Arthur

[History Education, UCL, Reino Unido]

Cobacho López, Ángel

[Derecho, UMU]

Egea Bruno, Pedro M. ${ }^{\text {a }}$

[Historia Contemporánea, UMU]

García Atienzar, Gabriel

[Prehistoria, UA]

González Monfort, Neus

[Didáctica de las Ciencias Sociales, UAB]

Haber Uriarte, María

[Prehistoria, UMU]

Hutson, Scott R.

[Anthropology, UK, EEUU]

Irigoyen López, Antonio

[Historia Moderna, UMU]

Mahony, Simon

[Digital Humanities, UCL, Reino Unido]

Marsilla de Pascual, Francisco Reyes

[Técnicas historiográficas, UMU]

Miralles Maldonado, José Carlos

[Filología Clásica, UMU]

Molina Gómez, José Antonio

[Historia Antigua, UMU]

Noguera Celdrán, José Miguel

[Arqueología, UMU]

Pérez Molina, Miguel Emilio

[Filología Clásica, UMU]

Prados Martínez, Fernando

[Arqueología, UA]

Sánchez Ibáñez, Raquel

[Didáctica de las Ciencias Sociales, UMU]

Sancho Gómez, Miguel Pablo

[Educación, UCAM]

Vilar García, María José

[Historia Contemporánea, UMU]

Zamora López, José Ángel

[Próximo Oriente Antiguo, CCHS-CSIC] 

Artículos

Los orígenes de la tecnología a debate: una revisión de las primeras industrias líticas.

Arturo Cueva Temprana.

De arqueología menorquina: Maria Lluïsa Serra Belabre y los círculos talayóticos de Sant Vicenç d' Alcaidús (Alaior, Menorca).

Octavio Torres Gomariz.

Nuevas cuestiones sobre el anfiteatro de Zaragoza.

José David Mendoza Álvarez.

Castidad o castigo. El estupro de las Vestales como símbolo de desorden social en Roma.

Juan Antonio Montalbán Carmona.

La Historia antigua en la Biblioteca de Focio.

Juan Luis Posadas Sánchez.

Usos sociales de la historia. La estrategia de Olga Cossettini, Rosario, 1935-1943.

Paula Caldo, Micaela Pellegrini Malpiedi y Agustina Mosso

Contribuciones a la didáctica de la Historia a través del método de análisis del objeto: como ejemplo... una "vasulla".

Nayra Llonch Molina y Verónica Parisi Moreno.

How are digital methods changing research in the study of the classical world? An EpiDoc case study. Katherine Steiner y Simon Mahony.

\section{Reseñas}

I Congreso Internacional "Creando ciudadanos, construyendo identidades. El uso del patrimonio material e inmaterial en la enseñanza de la historia."

José Díaz Serrano, Ainoa Escribano Miralles, Ana Isabel Ponce Gea y David Verdú González 151

Beckert, S. (2014). Empire of cotton: A global history. New York: Alfred A Knopf. 640 págs.

Ricky D. Mullins Jr..

Coumert, M. y Dumézil, B. (2013): Los reinos bárbaros en Occidente (traducción de Peinado Santaella, R. G.: Les royaumes barbares en Occident, Presses Universitaires de France, 2010). Editorial Universidad de Granada. Granada. 156 págs.

José Ángel Castillo Lozano.

La prehistoria en Las tres edades de Buster Keaton.

Alberto Lombo Montañés y Esther Rodríguez Ortiz.

Normas de publicación/Publishing rules 



\title{
Nuevas cuestiones sobre el anfiteatro de Zaragoza
}

\author{
New questions on the amphitheater of Zaragoza
}

José David Mendoza Álvarez ${ }^{1}$

Universidad de Sevilla

Recibido: $17 / 04 / 2016$

Aceptado: 01/08/2016

Para citar este artículo: Mendoza Álvarez, J. D. (2016). Nuevas cuestiones sobre el anfiteatro de Zaragoza. Panta Rei. Revista Digital de Ciencia y Didáctica de la Historia, 37-61.

ISSNe: 2386-8864

DOI: $10.6018 /$ pantarei/2016/3

\begin{abstract}
Resumen
Presentamos nuestra investigación relacionada con las recientes hipótesis que se han planteado sobre la existencia del anfiteatro de Caesar Augusta (Zaragoza), aportando pruebas y la ausencia de datos como punto de partida para determinar su existencia y posible ubicación correcta. Revisaremos las fuentes gráficas y tendremos en cuenta los paralelos de ciudades con el mismo estatuto jurídico, algunas de las cuales presentaban los tres edificios lúdicos, circo, teatro y anfiteatro, mientras que otras tan solo teatro y anfiteatro, hecho significativo a la hora de contextualizarlo en nuestro caso en el que contemplamos la posible existencia de mártires que nos pueda orientar a esclarecer el posible lugar de ubicación del anfiteatro caesaraugustano, bien en el interior del pomerium como en su exterior.
\end{abstract}

\section{Palabras clave}

Arqueología, Historiografía, Yacimiento, Historia de Europa, Historia.

\begin{abstract}
We present our research related to recent hypotheses that have been raised about the existence of the amphitheater of Caesar Augusta (Zaragoza), providing evidence and the absence of data as a starting point to determine its existence and possible exact location. We review the graphic fonts and take into account the parallels of cities with the same legal status, some of which had three recreational buildings, circus, theater and amphitheater, while others just theater and amphitheater, significant fact in order to contextualize it in our case where we contemplate the possible existence of martyria, which can help us clarify the possible site for the caesaraugustano amphitheater, well inside the pomerium or beyond it.
\end{abstract}

\section{Key Words}

Archaeology, Historiography, Historic sites, European History, History.

1 Para contactar con el autor: José David Mendoza Álvarez. Universidad de Sevilla. Dpto. de Prehistoria y Arqueología. luckyman76@hotmail.com. 


\section{Introducción}

En esta investigación se establecerán determinadas respuestas a la posible ubicación del anfiteatro de Caesar Augusta que lo ubican en la Plaza de los Sitios o bajo el hotel Palafox (Galve, 2004; 2014; Beltrán Llorís, 2007-2008; Diarte et al., 2013), sin que sean hipótesis determinantes para ello. De la misma forma se atenderá a las imágenes en las que se basan para establecer un lugar indicado de la supuesta ubicación del edificio de espectáculos, así como otras ilustraciones. Se tendrá en cuenta los resultados de la prospección realizada mediante georradar y se interpretarán los resultados de las mismas. Por último, se intentará conocer los detalles del supuesto plano anónimo que ubica unas estructuras bajo el hotel Palafox de Zaragoza, donde se aprecian unos restos que se interpretan como un posible anfiteatro, sin más datos al respecto, aludiendo a la supuesta confidencialidad de los resultados de las excavaciones que en su día realizaron en el lugar para la construcción del hotel.

\section{Primeras intervenciones}

Fue A. Beltrán quien puso los pilares de la arqueología zaragozana, comenzando un periodo, no sin lagunas en cuanto a intervenciones y publicaciones, que pretendían conocer el pasado de la ciudad (Gascón, 2009; Galve, 2014). El propio Museo de Zaragoza es el encargado de realizar parte de las excavaciones para determinar la Forma Vrbis de la ciudad romana de Caesar Augusta (Beltrán Llorís, 2004), aunque los trabajos pioneros respecto al valle del río Huerva, se deben al Dr. M. Pellicer en 1957 (Pérez, Fanló y Picazo, 2010). Posteriormente las excavaciones se han centrado en el casco histórico (Galve y Blanco, 2002) de la actual Zaragoza, en la Plaza de la Seo y en la Plaza de D. Jaime I, para delimitar la ordenación urbana en torno al foro, y la red viaria (Hernández Vera y Núñez, 1997; Hernández Vera y Núñez, 2000). Entre 1998 y 2003 se excavó el teatro (Beltrán Llorís, 1993; Galve, 2004; 2014) y se empezó a conocer algunos tramos de las cloacas (Escudero y Galve, 2013). Así mismo se han realizado catas arqueológicas también en los solares de las Tenerías $n^{\circ}$ 3-5 (Cebolla, Domínguez y Ruiz, 2004). De esta forma se ha llegado a establecer los niveles más antiguos desde la Edad del Bronce, determinándose una ocupación prerromana en el solar 26 de la calle Palafox (Hernández Vera y Núñez, 2000) donde se han excavado restos de un poblado que se adapta a la orografía circundante, con casas de planta rectangular. Esta disposición del relieve fue representada en el siglo XIX por Casañal al realizar un levantamiento topográfico (Figura 1) de la zona, destacando los desmontes y aterrazamientos que se iniciaron con la ocupación romana (Hernández Vera y Núñez, 2000). Se constatan acondicionamientos del terreno para evitar inundaciones, mediante drenajes con ánforas y estructuras hidráulicas (Beltrán Llorís, 2007-2008; Galve, 2014). Los restos iberorromanos se extienden hacia el río Huerva, llegando a detectarse pavimentos de opus signinum en la calle Viejos (Hernández Vera y Núñez, 2000). En la calle Mosen Pedro Dosset fueron halladas inhumaciones paleocristianas en fosa, revestidas con tejas planas, ataúd de madera, sin ajuar, con una cronología entre los siglos IV y $\vee$ (Galve y Blanco 2001-2002). Se conocen también algunos vertederos con material cerámico (Diarte, 2014). El patrimonio zaragozano ha sido puesto en valor, además, prácticamente desde los años noventa del siglo XX con la realización de cuatro museos de sitios en el foro, termas, puerto fluvial y teatro (García, Casteels y Erice, 2007). 


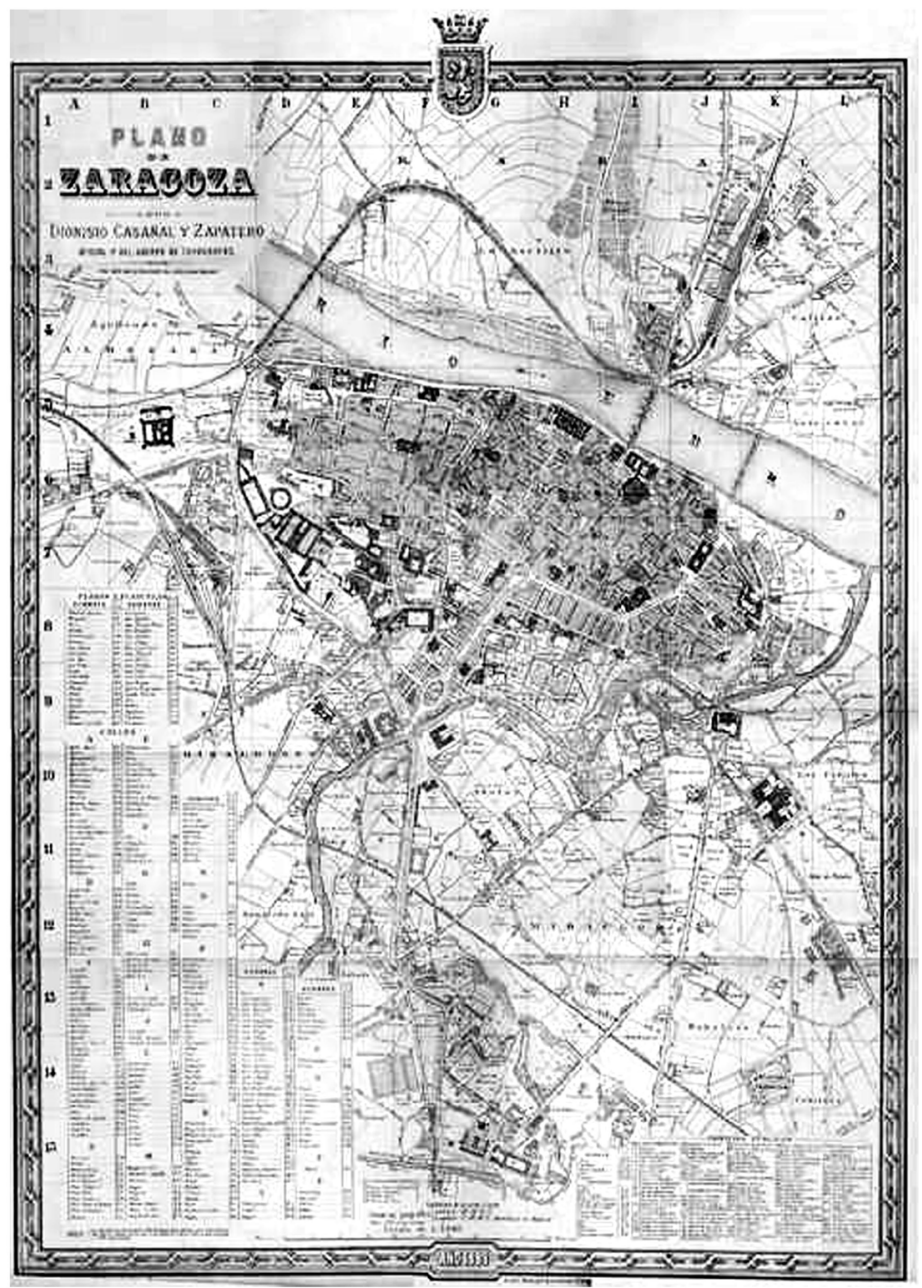

Figura 1: Plano de Casañal de 1880. Fuente: extraído de http://planosymapasdearagon.blogspot.com.es/.

\section{Aspectos puntuales para el conocimiento de Caesar Augusta}

Gracias a todas estas intervenciones zaragozanas, y a pesar de la existencia de muchas noticias e imprecisiones, se conocen numerosos datos para afirmar la existencia de una ciudad indígena previa, denominada Salduie, ubicada en las orillas del Ebro y cercanías del afluente Huerva, lo que la convertía en un lugar estratégico donde confluían las primitivas rutas (Magallón, 1990; Gómez Pantoja, 1994; Escudero y Galve, 2013), recogido por Estrabón (II, 2.15) y Plinio (Nat. Hist. III, 24) aludiendo a una población previamente romanizada antes del asentamiento definitivo romano (Gómez Pantoja, 1994; Galve, 2004; 2014; Beltrán Llorís y Velaza, 2013). Este hecho fue aprovechado con dicha ocupación sobre el poblado indígena, mejorando la urbanística y controlando las rutas de comunicaciones terrestres y fluviales (Magallón, 1990; luste, 1993), por tres de las ocho legiones que habían intervenido en las guerras cántabras, siendo la IV Macedonica, VI Vitrix y $X$ Gemina (Gómez Pantoja, 1994; Fatas, 1998; Beltrán Llorís, 2007-2008; Ortiz y Paz, 2009).

La nueva ciudad se erigía en una planta hipodámica con el trazado peculiar que se realizaba en la fundación de una colonia, establecida entre los años 15 y 14 a. C. (Gómez Pantoja, 1994; Ortiz y Paz, 2009; Cebolla, Domínguez y Ruiz, 2014; Galve, 2014), realizándose previamente el acondicionamiento del terreno y la red de cloacas sobre las que se erigían las viviendas y los edificios públicos y privados, siendo necesario tomar medidas para evitar las inundaciones del río (Galve, 2014). Con el tiempo, esta ciudad aumentó su perímetro hacia el este (Beltrán Llorís, 1993; 
Gómez Pantoja, 1994; Hernández Vera y Núñez, 2000; Galve 2004). La ciudad se convirtió en capital de su Convento Jurídico (Andreu, 2003; Beltrán Llorís, Mostalac y Paz, 2009; Ortiz y Paz, 2009; Sevilla, 2009), controlando las rutas comerciales y paso de los Pirineos, Teruel, valle del Segre y la costa cantábrica (Fatas, 1998; Beltrán Llorís, Mostalac y Paz, 2009).

Su auge perduró hasta el siglo III en el que debido a las dificultades económicas tuvo que contraerse, lo que no implicó que fuese abandonada, sino que en época tardía, la ciudad necesitó nuevas transformaciones urbanísticas, pues con la anulación de la red de alcantarillado que se constata en las excavaciones arqueológicas realizadas (Galve, 2004), se incrementó el nivel estratigráfico elevando la cota de uso y generalizándose vertederos intraurbanos (Diarte, 2014).

Esta transformación tardía pretendía mantener sus edificios y monumentos aunque, de forma general, con la crisis del siglo III, esto resultaba muy costoso. De esta forma, se constata que el teatro sería el primer edificio en perder su funcionalidad y el circo lo haría en último lugar, y para el caso caesaraugustano podemos señalar que se tiene constancia de una fuente escrita del 504 que indica la celebración de juegos circenses (Beltrán Martínez, 1976). Además, junto a los circos, los anfiteatros fueron edificios que también permanecieron durante momentos tardíos a pesar de que el cristianismo, implantado desde el siglo IV (Beltrán Martínez, 1976), había prohibido ya estas actividades (Diarte, 2014, pp. 99-100). Debemos preguntarnos, por tanto, si habría que buscar un circo y un anfiteatro en Caesar Augusta, o si tan sólo presentaría esta colonia teatro y circo.

Las termas caesaraugustana de la calle Ossau fueron abandonadas en el siglo III y reocupadas como viviendas en el IV junto al foro y al teatro, aunque a pesar de esto, se constata que sus murallas fueron reparadas en el momento que se expoliaban otros edificios (Beltrán Martínez, 1976; Diarte, 2014). Esta crisis provocó, además, el abandono de las villas suburbanas, residencias privadas y mansiones rurales (Beltrán Llorís, Mostalac y Paz, 2009; Hernández Vera y Núñez, 2000; Diarte et al., 2013).

\section{Análisis de hipótesis}

En primer lugar hay que indicar que la investigación realizada por Diarte y su equipo en 2003 (Diarte et al., 2003) plantea una hipótesis en la que no se aportan pruebas materiales, literarias o epigráficas, dándose por supuesto la existencia de los tres tipos de edificios de espectáculos en las ciudades romanas por lo que recientemente ha sido descatada (Galve, 2014). De la misma forma, se proponen paralelos no claros a día de hoy, como el anfiteatro de Córdoba, en detrimento del anfiteatro de Italica (Santiponce, Sevilla), paradigmático edilicio de la Baetica en el que gracias a una investigación reciente que hemos realizado sobre unos 474 edificios anfiteatrales en la órbita romana, el propio italicense se encuentra en el cuarto puesto del ranking de los mayores anfiteatros, superado por el Coliseo, Capua y Narbona y siendo el mayor de la Península lbérica, pues el anfiteatro de Corduba que se pensaba mayor, ha sido comprobado que presenta un posible error de interpretación estructural, quedando por debajo de las dimensiones del italicense (Hidalgo, 2012; Diarte et al., 2013).

No entraremos en detalles sobre los edificios anfiteatrales de la Bética, pero señalaremos Italica y sobre todo Corduba a modo de referencias, en distintas ocasiones, para conocer los pormenores que podrían acercarnos a determinar la existencia de un anfiteatro en Zaragoza. De forma tradicional se acepta que el final de la II Guerra Púnica en la Península Ibérica tuvo lugar en llipa Magna (Alcalá del Río, Sevilla), lo que aprovecharon los romanos para fundar su primera colonia en un enclave estratégico al sur de la misma, capaz de controlar las rutas terrestres, fluviales e incluso las marítimas ${ }^{2}$, denominándola Italica por la procedencia de los soldados acantonados en ella y citada por Estrabón (III, 2.2) como una ciudad que consiguió gran importancia tras Corduba, Gades e Hispalis (Rodríguez Gutiérrez y García Fernández, 2016). De esta forma, gracias a la existencia de anfiteatros en Italica y Corduba, se pretende ver anfiteatros en las grandes capitales,

2 Gracias a la ensenada del Guadalquivir, el mar llegaba hasta la propia Spal (la Sevilla indígena). 
como Gades e Hispalis (Jiménez Hernández, 2015), pudiendo extender esta hipótesis al resto de ciudades y colonias con cierta relevancia en la Península lbérica, donde se incluiría el caso de Caesar Augusta.

Sobre Córdoba existe una monografía del anfiteatro descubierto y excavado en un mínimo sector, realizada por los doctores D. Vaquerizo y J. F. Murillo en 2011 que presenta errores de interpretación respecto al tema en cuestión, pues determina unas dimensiones excesivas para el anfiteatro cordobés que comprende $178 \times 154 \mathrm{~m}$. como medidas máximas, y $96 \times 73 \mathrm{~m}$. para su arena, lo que le situaría en el ranking anfiteatral en el segundo puesto, por debajo del Coliseo, proponiéndose en este estudio que el edificio se erigiría desde los niveles de la arena, con una estructura maciza realizada mediante muros de sillerías y rellena de escombros (Vaquerizo y Murillo, 2011) lo que dificultaría la construcción de los niveles superiores según la interpretación más reciente de los restos que fueron excavados (Jiménez Hernández, 2015), por lo que debe entenderse como una estructura de menor tamaño en el que la ima cavea y podium debían estar excavados, presentando un diseño similar al italicense, no siendo construido como una estructura maciza y mostrando las dimensiones máximas más apropiadas de 145 x 121,8 m. y 69,6 x 46,4 m. de arena (Jiménez Hernández, 2015).

El tamaño del mismo también ha sido cuestionado por el Dr. Rafael Hidalgo ${ }^{3}$ al demostrar que "nada permite descartar que el anfiteatro contara con un anillo más hacia la arena que confirmaría en realidad el podium" (Hidalgo, 2012, p. 262). Determina contradicciones en las propias dos secciones reconstructivas y publicadas del anfiteatro, pues en una se establecen siete anillos y en otra seis, de la misma forma que aporta pruebas respecto a otros puntos, y paralelos conforme a los planos publicados del anfiteatro de Córdoba, pues "el muro exterior podría formar parte de una estructura singular vinculada a la zona delantera o bien corresponder a una construcción perimetral vinculada al tránsito de espectadores" (Hidalgo, 2012, p. 262), añadiendo como paralelo los anfiteatros de Capua o Catania, además de Nimes, Salona, el propio Coliseo o Luni (Garriguet, 2010).

La problemática del anfiteatro cordobés radica en que se le quiso ubicar en distintos sitios de la ciudad, de la misma forma que se pretende para el caso caesaraugustano, hecho por el que lo traemos a colación. D. Luis Maraver lo pretendía ubicar en la calle Correduría de Córdoba, así como Puchal lo señalaba en la Plaza de la Almagra (Sánchez, 2006), y finalmente se le ubicó en el sitio donde se encontraba la antigua Facultad de Veterinaria (Hidalgo, 2008; Garriguet, 2010), de forma extraurbana al no existir espacio en el interior del recinto amurallado, de la misma forma que en Zaragoza, y con orientación suroeste (Garriguet, 2010). Esta falta de consenso provocó que se afirmase que la capital de la Bética debía existir más de un anfiteatro al igual que sucede en Puteoli, Carnuntun o Vtica (Sánchez, 2006).

Fuera de la Bética nos encontramos con el caso de Barcelona que, de la misma forma que en Córdoba, se pretende localizar un anfiteatro extraurbano, ubicado en distintos lugares como el sitio donde se levanta la iglesia de Santa María del Pi (Conde, 2013), o el de la iglesia de Santa María del Mar, antes denominada como Santa María de las Arenas, junto a una necrópolis tardoantigua relacionada con el enterramiento de Santa Eulalia (Sales, 2011; Conde, 2013), queriendo ver de esta forma una fosilización urbanística para determinar la existencia de un anfiteatro de trazado elíptico y poniendo como paralelos los casos de Lucca, Florencia y la propia Córdoba (Sales, 2011 Conde, 2013; Escudero y Galve, 2013), además de quererlo relacionar con un espacio martirial de la misma forma que se quiere ver en Zaragoza con el caso de Santa Engracia (Galve, 2014) o el obispo Osio para Córdoba, en el que las pruebas arqueológicas determinan que, para este último caso, lo que se pretendía ver como una estructura martirial compuesta por ábsides, no era más que los contrafuertes conectados con el muro del podium desde los primeros momentos de la

3 Este artículo del Dr. Hidalgo es un ejemplo de cómo manejar las pruebas de las que dispone el investigador para contrastar las mismas e ir descartando hipótesis, y hasta el momento en el que se demuestre la verdadera existencia del podium del anfiteatro cordobés, no se debe desbancar al anfiteatro de Italica del ranking de los mayores anfiteatros del Imperio, y por supuesto, del mayor y mejor conservado de la Península Ibérica. 
construcción del anfiteatro, lo que no responde a este hecho y desmonta la teoría (Hidalgo, 2012; Jiménez Hernández, 2015).

Pero vayamos por partes respecto al anfiteatro de Zaragoza. En primer lugar hay que destacar la ayuda que la epigrafía nos podría aportar para ello, a través de la consulta de la base de datos especializada Clauss-Slaby. No se debe descartar esta fuente de primer orden aunque hasta el momento no se ha encontrado ninguna alusión ni a las actividades lúdicas, gladiatorias, ni a posibles magistrados o evergetas que aporten pistas para conducirnos hasta tal afirmación de la existencia de un anfiteatro en Caesar Augusta. Por tanto, partimos de la no existencia de ningún edificio arquitectónico de este tipo en la colonia caesaraugustana, aunque no podemos descartar la construcción en materiales perecederos o provisionales. En este caso, la arqueología tampoco aporta nada hasta el momento, y los resultados del georradar son indeterminados debido a la existencia de infraestructuras hidráulicas para adaptar el terreno, que condicionan los resultados (Galve, 2014). Por tanto, no existen restos materiales que aporten pistas para la ubicación del edificio en las zonas suburbanas de la ciudad como se apuntó (Diarte et al., 2013).

\subsection{Sobre edificios lúdicos y su funcionalidad}

A modo de control de masas, se erigieron distintos tipos de edificios lúdicos, aunque en primer lugar estas actividades se daban en contextos diversos, como el foro para el caso romano, construyéndose los primeros anfiteatros en madera y posteriormente en material pétreo (García Naranjo, 1951; Melchor, 1994). Se erigieron teatros, circos y anfiteatros, siendo para estos últimos el anfiteatro Flavio el modelo a seguir desde su construcción, que presentaba una solución arquitectónica para construir en altura con mayor resistencia, como lo era el uso del arco y la bóveda que le permitía a la estructura soportar el peso, las tensiones y los empujes (Gros y Torelli, 2007; Naselli, 2010).

No obstante, el precedente de los juegos debemos buscarlo en el mundo griego donde aparecieron las competiciones atléticas y luchas, siendo modificadas por los etruscos para contextos funerarios, y adoptado por Roma que lo utilizó, además, como control político y religioso (Fabié, 1892; Blázquez, 1994; 2006; Ceballos y Ceballos, 2003; Ceballos 2007a; 2007b; Martín Escorza, 2008; Santos Yanguas, 2008; Cabrero y Cordente, 2011; González Acuña, 2011). Estos espectáculos se volvieron extremadamente violentos (Ceballos y Ceballos, 2009), dándose luchas gladiatorias, cacerías de animales, combates navales en edificios preparados a tales efectos, pantomimas, representaciones teatrales en los teatros o carreras de caballos en los circos (Cabrero y Cordente, 2011). Para los anfiteatros se constatan combates gladiatorios, cacerías, ejecuciones, llegándose a exhibiciones acrobáticas y carreras de caballos e incluso a representaciones teatrales (Garrido, 2005; Ceballos y Ceballos, 2009), convirtiéndose estos edificios en un símbolo para la sociedad romana (Gros y Torelli, 2007).

El hecho de que una ciudad fuese colonia o capital importante (Diarte et al., 2013) no implica que en ella debiera existir los tres tipos de edificios lúdicos comentados. De hecho, existen numerosos ejemplos donde no se da esta ecuación (González Acuña, 2011), como en Calahorra, donde se conoce el circo, Barcino de la que hemos comentado la problemática existente sobre el anfiteatro, Saguntum que presenta un circo y teatro pero no anfiteatro, Toletum con anfiteatro y circo pero sin teatro y otros núcleos como Valentia, Lucentum, Cartago Noua, Acinipo, Baelo Claudia, Carteia, Gades o Malaca (García y Bellido, 1961-1962; Gómez Pantoja, 1978; Hernández López y Pascual, 1995; Rodríguez Gutiérrez, 2009; Gurt y Diarte, 2012; Conde, 2013).

\subsection{Respecto a la supuesta ubicación bajo el Hotel Palafox}

Se habla del plano del anfiteatro de Caesar Augusta bajo el Hotel Palafox (Figura 2), publicado en el Heraldo de Aragón el 24 de abril de 2011 (Diarte et al., 2013), hechos que no han sido confirmados 
oficialmente (Galve, 2014). En la edilicia pública romana era habitual que se construyera con el mismo espesor y profundidad los cimientos (Hidalgo, 2012), de manera que la planta del supuesto anfiteatro bajo el hotel Palafox debe descartarse al detectar distintas alineaciones asimétricas, con distinto grosor de cimentación y por supuesto, sin conocer nada sobre su estratigrafía que indique la superposición de los restos conforme a un orden cronológico. No es posible determinar la existencia de los materiales que hubo de su relleno, ni los restos cerámicos que son fundamentales para fechar un yacimiento, por lo que ante esta carencia encadenada de errores, se debe desechar toda teoría que quiera ver en ese plano un edificio anfiteatral de época romana para Caesar Augusta.

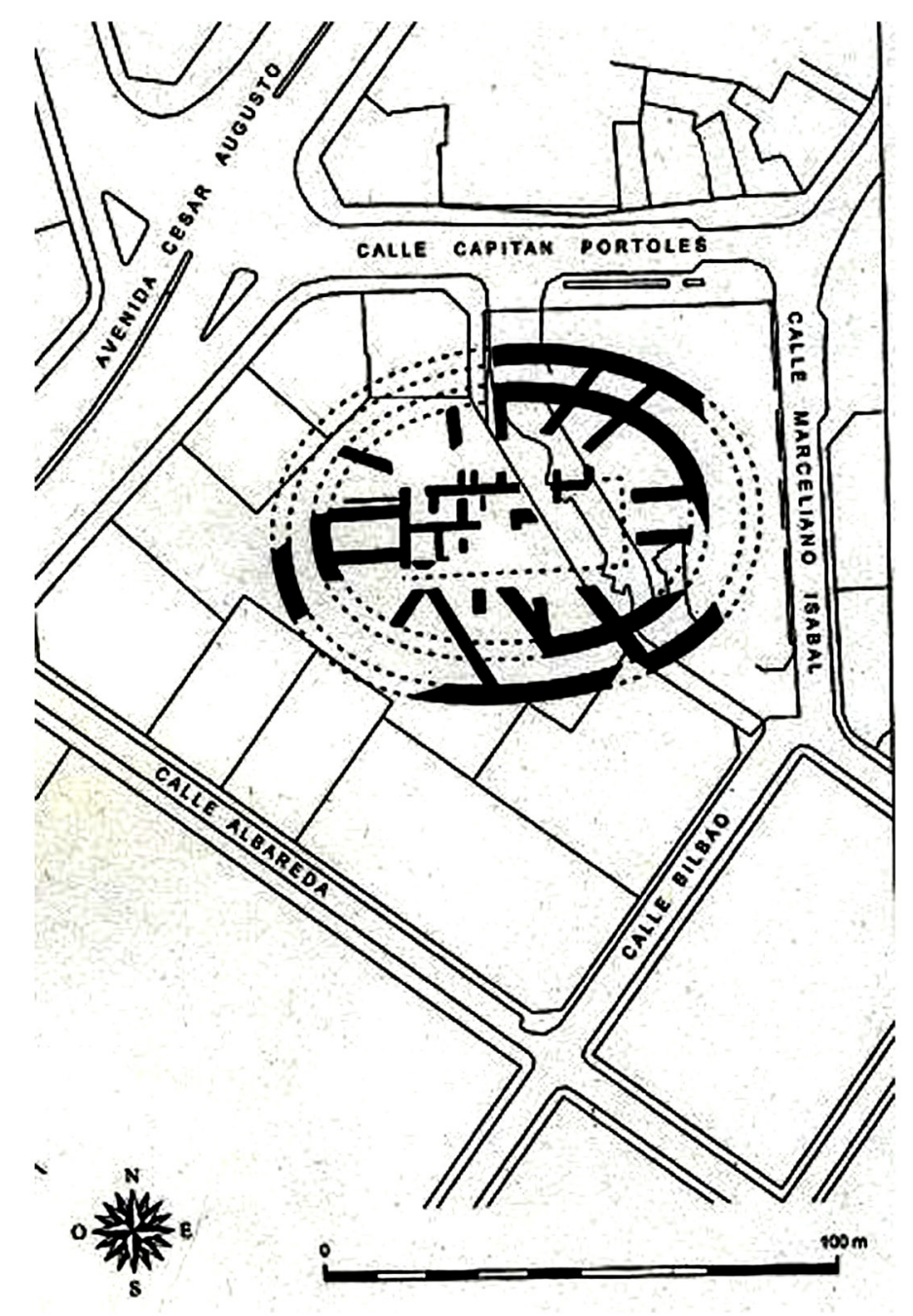

Figura 2: Plano del supuesto anfiteatro bajo el solar del Hotel Palafox Fuente: http://aragonromano.blogspot.com.es/.

\subsection{De la supuesta localización en la Plaza de los Sitios y sus alrededores}

Ante la escasez de fuentes de primer orden, las investigaciones hasta el momento, se basan en el plano de Casanova (Diarte et al., 2013), el cual no podemos aceptar como fuente para nuestro caso. En primer lugar nos muestra una alineación de olivos en un sector de este plano (Figura 3), que toma una alineación arqueada. Se plantea desde un primer momento como el lugar ideal para la ubicación de un edificio elipsoidal con los siguientes errores. 


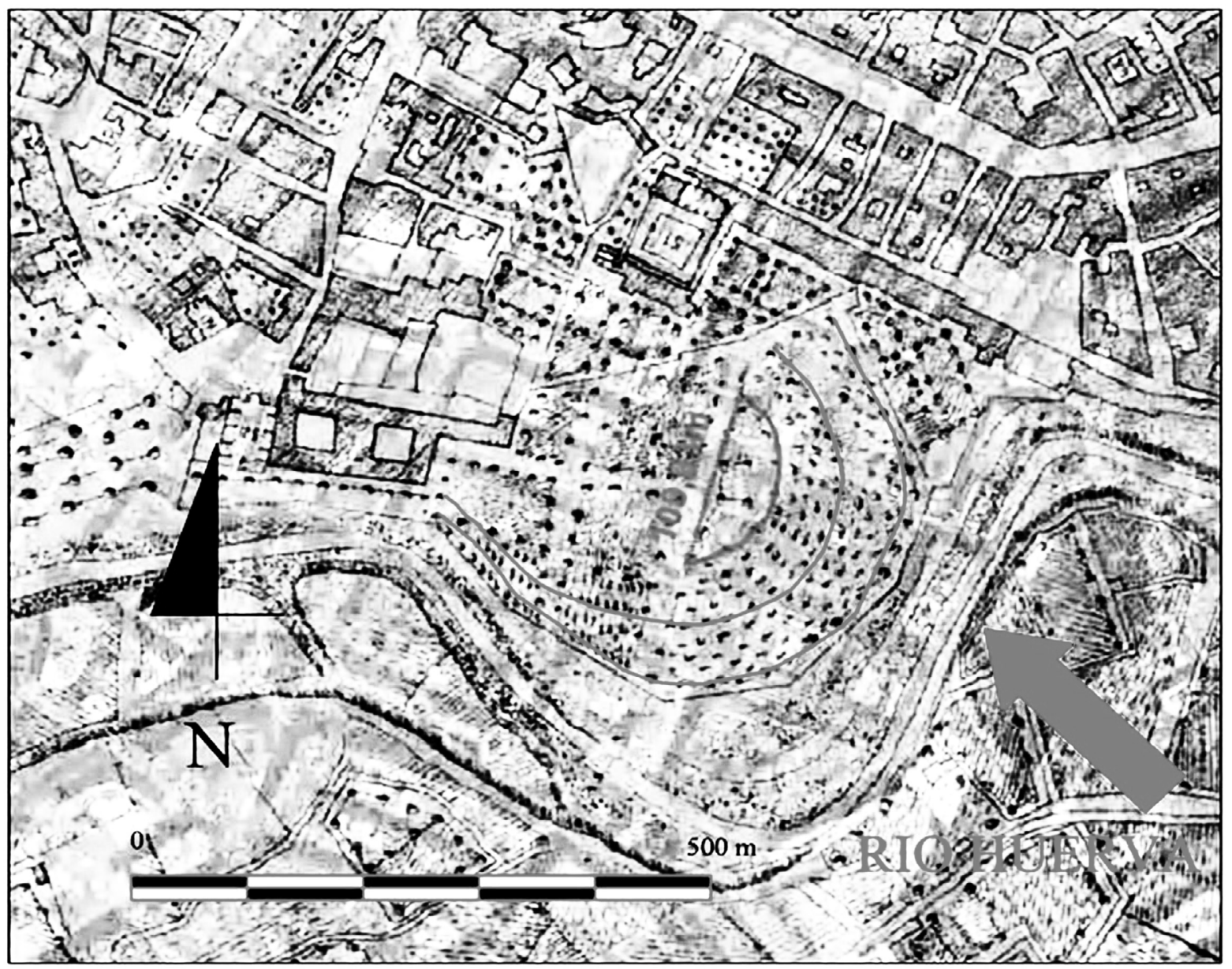

Figura 3: Plano de Casanova (Diarte et al., 2013) y la hipótesis de Diarte y su equipo.

Fuente: extraído de http://www.pyrenae.com.

En primer lugar, la distribución de las plantaciones se adecua a la topografía del terreno en el que el propio curso del río Huerva hace configurar este espacio con una forma muy característica y común en todos los ríos del mundo. En segundo lugar, se alude a una canalización en el margen del río de dudosa existencia (Diarte et al., 2013). Hay que tener en cuenta que para corregir la pendiente de la ciudad hacia el río, se realizó una extensa red de vertido de aguas como ya se ha visto anteriormente (Beltrán Llorís, 1993), lo que viene a coincidir con la acción antrópica hallada por el georradar en estas últimas investigaciones. Se debe señalar que el trazado del decumano de la ciudad de Caesar Augusta corresponde con las actuales calles Manifestación, Espoz y Mina, y Mayor; de la misma forma que el cardo se fosiliza en la calle Don Jaime I, por lo que gracias a ello podemos establecer la red de cloacas interurbana (Gómez, Parruca y Ros, 2009) las cuales enlazarían con las infraestructuras hidráulicas exteriores (Figura 4), siguiendo la pendiente adecuada para verter los residuos en el río (Escudero y Galve, 2013; Galve, 2014).

En tercer lugar, contemplamos que en otros planos de la época (Figura 5) se aprecia el mismo dibujo, aunque con un trazado lineal en la mencionada plantación, por lo que la teoría inicial se desmonta también de esta forma.

Se habla de una construcción en piedra que ocuparía la Plaza de los Sitios y aledaños (Diarte et al., 2013), que no se aprecia sobre ningún plano. Sin embargo era habitual el aterrazamiento de las zonas en las que se establecían estructuras antrópicas, tales como las que refiere $\mathrm{M}$. Beltrán con las comentadas infraestructuras hidráulicas (Beltrán Llorís, 1993; Gómez Pantoja, 1994; Hernández Vera y Núñez, 2000; Gómez, Parruca y Ros, 2009). 


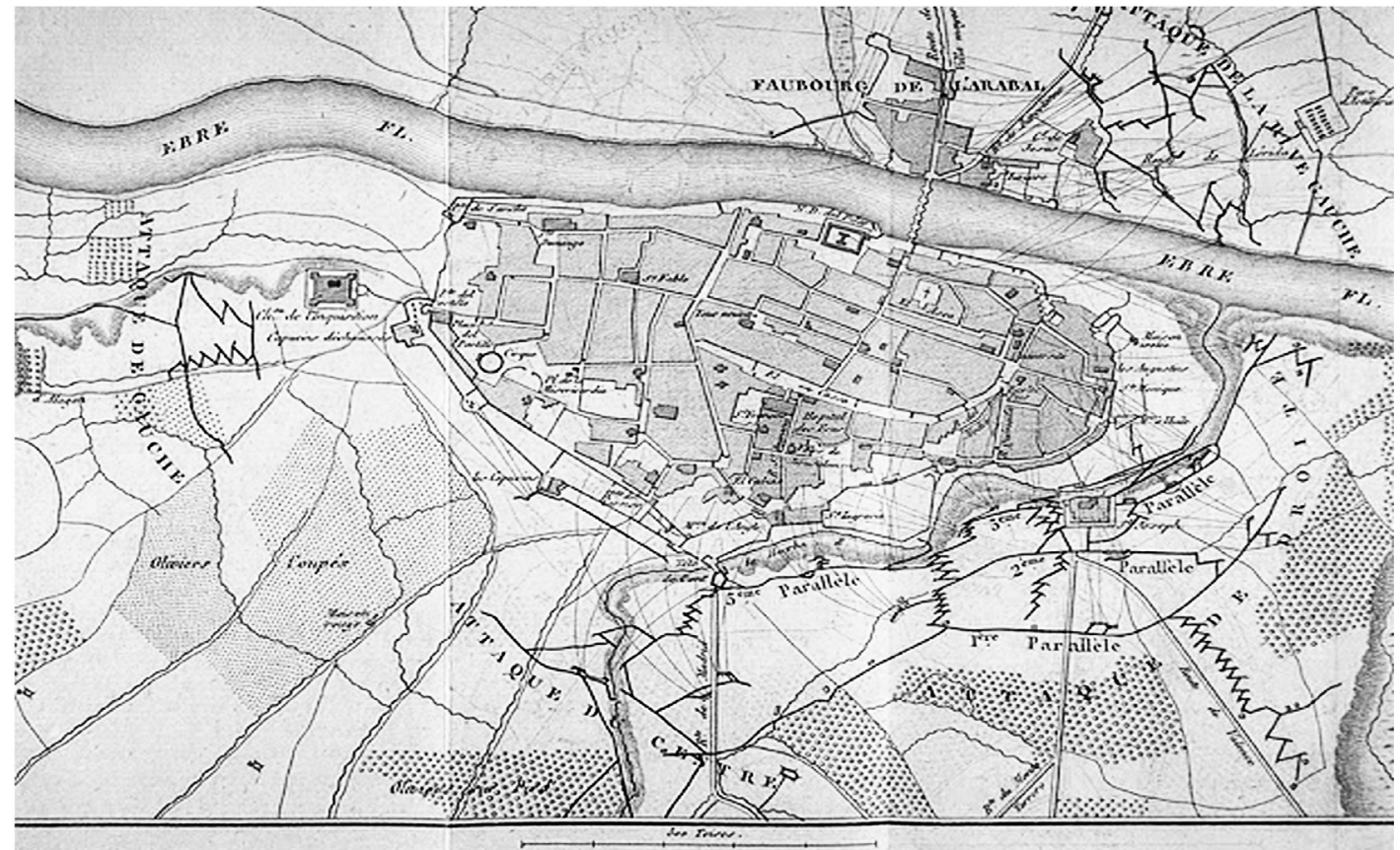

Figura 4: Plano de Monín de 1808 donde se aprecian posibles canalizaciones en el entorno estudiado de Caesar Augusta. Fuente: http://planosymapasdearagon.blogspot.com.es/.

En cuarto lugar, se habla de "diámetro" cuando lo correcto sería hablar de eje mayor y eje menor para indicar un edificio de trazado oval o elíptico. Se comenta que posee un "diámetro de 110 m." (Diarte et al., 2013, p. 123) afirmando que se trata de un anfiteatro localizado en esta zona. En primer lugar, un diámetro refiere a una figura geométrica conocida como "circunferencia", pues un diámetro es un segmento de recta que pasa por el centro, uniendo dos puntos opuestos en una circunferencia, superficie esférica o curva cerrada ${ }^{4}$. Y en segundo lugar, los anfiteatros solían ser construidos a partir de una forma arquitectónica elipsoidal u ovalada como evolución desde los espacios rectangulares hacia una forma funcional en la que se mejoraría la vista del espectáculo desde cualquier sector del graderío (Wilson, 1993) (Figura 6).

Este simple pero debatido hecho sobre la planta elíptica u ovalada, tiene su fundamento arquitectónicamente pues a la hora de construir elipses concéntricas para un edificio de grandes magnitudes como podía ser un anfiteatro, se llegaba a errores respecto a la inclinación de las gradas y curvatura de sus muros radiales que en cambio no ocurría si lo que se planteaba desde su base era un óvalo como forma compuesta (Wilson, 1993). La elipse se genera desde dos puntos focales sobre su eje más largo, lo que confiere al edificio una configuración cronológica más antigua y básica, como en Carnuntum, Vetera, Lambaesis y Saintes (Wilson, 1993; Jiménez Hernández, 2015). En cambio, con el óvalo se puede generar dos pares de puntos focales en cada uno de los ejes, lo que vendría a establecer una planta compleja de ocho puntos como en el Coliseo o Salona, o de cuatro puntos como en Pola, Verona, Capua, El Djem, Nimes, Arles o Pozzuoli (Wilson, 1993). Esta complejidad se establecía mediante dos sistemas de construcción muy similares, denominados "plantas con triángulo pitagórico inscrito" y "plantas con triángulo equilátero" (Wilson, 1993), que no vendremos a discutir en esta ocasión puesto que no tenemos los más mínimos vestigios para partir con alguna propuesta constructiva.

4 Vid http://lema.rae.es/drae/?val=diametro 

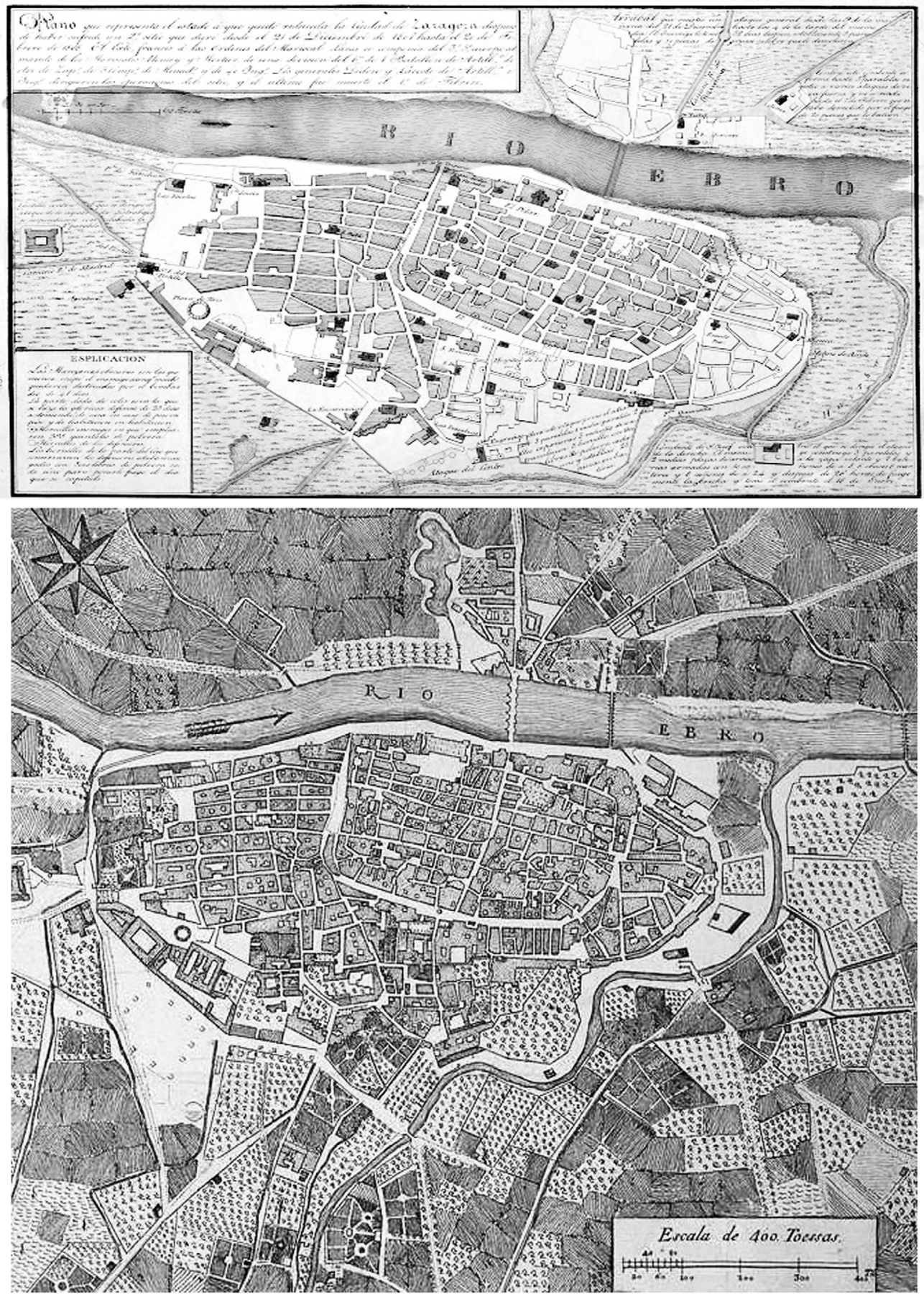

Figura 5: Plano de Santiro de 1814 (parte superior) donde se observa una alineación regular y no elipsoidal de la linde de olivos, como se pretende ver. Plano Anónimo del siglo XVIII (parte inferior) donde se aprecia también las lindes rectas de olivos en la zona estudiada.

Fuente: http://planosymapasdearagon.blogspot.com.es/. 

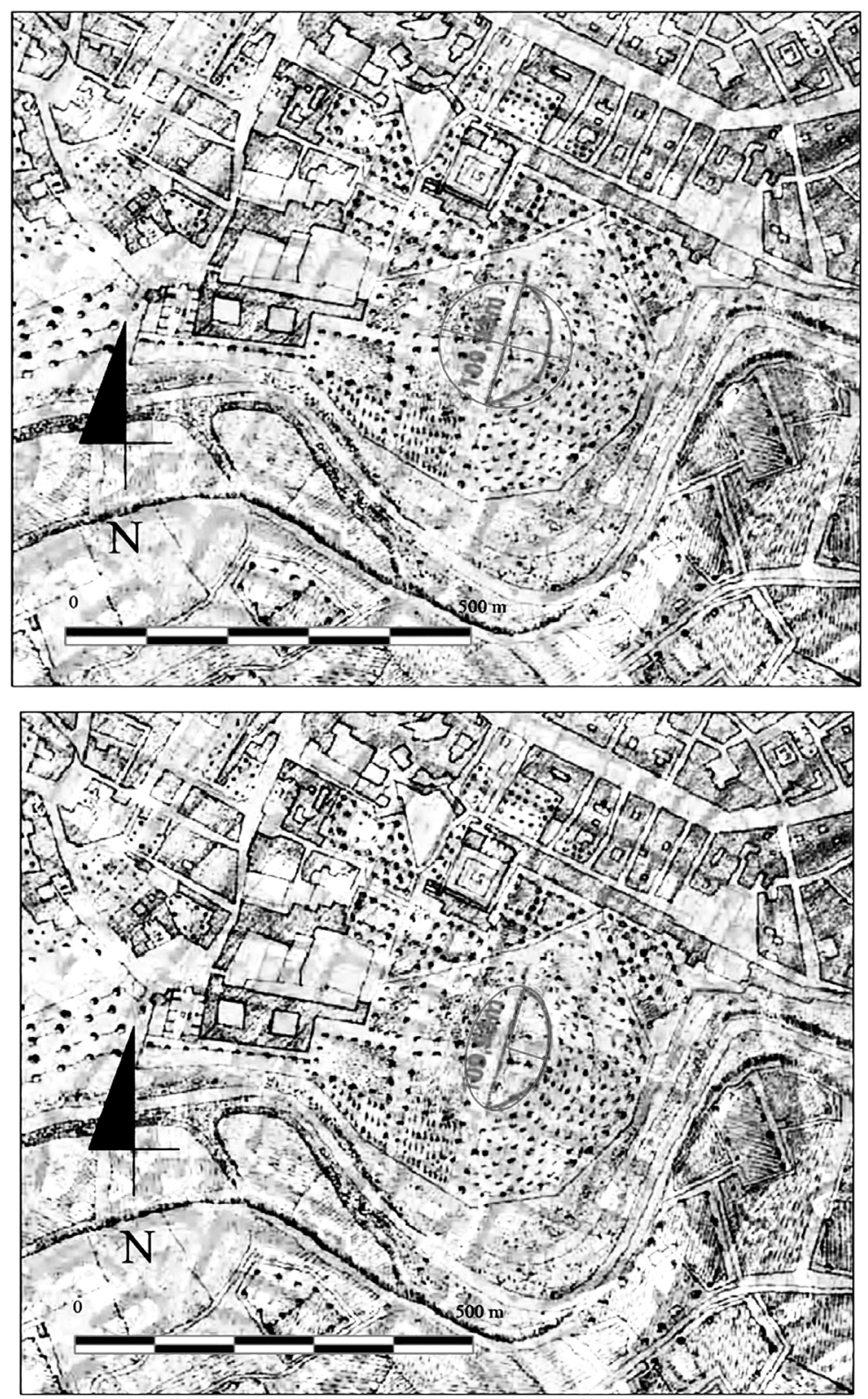

Figura 6: Relación establecida por el autor sobre la hipótesis de Diarte y su equipo, que proponen una elipse con un diámetro de $110 \mathrm{~m}$ (arriba), cuando lo correcto sería hablar de diámetro de circunferencia, dando como resultado el indicado en esta figura. Propuesta del autor (abajo) sobre la hipótesis de Diarte y su equipo, lo que se vendría a obtener un eje mayor de 109,9 $\mathrm{m}$ y un eje menor de $66,6 \mathrm{~m}$, lo que nos vendría a dar unos $366,3 \times 222$ pies romanos (teniéndose en cuenta que un pie romano lo hemos redondeado a 0,30 m). Fuente: Diarte et al., 2013.

\subsection{Evolución urbanística de Caesar Augusta}

Se conocen unas sesenta viviendas caesaraugustanas que corresponden a los momentos cronológicos de los siglos I a. C. y V d. C., aunque no se tiene ninguna planta completa de ninguna de ellas. En cualquier plano del núcleo urbano romano (Beltrán Llorís, Mostalac y Paz, 2009; Diarte, 2014; Galve, 2014), se puede apreciar el río Huerva el cual deja muy poco espacio material para la ubicación de un anfiteatro conforme se quiere ver para la Plaza de los Sitios, donde también habría de tenerse en cuenta la movilidad natural del propio río, la sedimentación que ello provocaría, y las 
obras de aterrazamiento que serían de especial importancia a la hora de ampliarse el suburbio de la ciudad en ese sector, para el reaprovechamiento de los recursos naturales (Beltrán Llorís, Mostalac y Paz, 2009) (Figura 7A, B y C).

Si nos detenemos a observar en un plano de Zaragoza los restos romanos de Caesar Augusta localizados hasta el momento, se apreciará que todos los elementos conforman un núcleo muy aglomerado, limitado por sus murallas, con espacios para edificios termales, para los templos, el foro, teatro, ínsulas y domus, además del puente sobre el Ebro, el puerto fluvial, el entramado de cloacas bajo las calles fundamentales hipodámicas, o las obras de drenajes del río (Gómez, Parruca y Ros, 2009; Dirate, 2014), lo que nos indica la falta de espacio a la hora de construir un edificio anfiteatral, por lo que sería acertada la idea de buscarlo en el exterior del núcleo urbano, en el supuesto de su existencia.

Las referencias que se realiza respecto a una villa en cuestión, es la aparición casual de opus teselatum y lo que determina como pavimentos de un cubiculum y un posible martyrium (Diarte et al., 2013), y se especifica que respecto a este edificio vinculado con los mártires, A. Mostalac realizó una intervención en el 2008 (Diarte et al., 2013). Se detecta, sin embargo, una escasez de enterramientos de los primeros cristianos en torno a estos lugares sagrados (Galve y Blanco, 2002). Contrastaremos los datos que tenemos y sobre todo los que están ausentes, para entender esta situación.

Para ello, se hace referencia a un "edificio romano" (Figura 8) por la zona donde se expoliaron sus columnas que utilizarían para la construcción de la cripta de Santa Engracia (Diarte et al., 2013), por lo que se creía que Encratis era la patrona de la ciudad aunque esta hipótesis fue descartada (Fatas, 2013). No obstante, esta estructura fue modificada con el tiempo, pasando de martyrium (Galve, 2014) a basílica, iglesia baja con cripta, iglesia alta, monasterio de monjes jerónimos, con biblioteca, claustro, huerta y pozo de las primeras reliquias martiriales, constatándose que el busto de Santa Engracia fue regalado por Benedicto XIII que lo trajo desde Génova en 1405 (Fatas, 2013).

Esta cuestión es difícil de entender, por otra parte, si se quiere ver el anfiteatro como el "edificio romano expoliado" pues las columnas solían estar adosadas o talladas en la propia estructura de la fachada como los ejemplos de Pola, Verona, Coliseo, Pozzuoli, Nimes, Arles, Capua, Italica, Salona y El Djem (Wilson, 1993) ${ }^{5}$ y para el caso de los grandes anfiteatros, existían columnas de orden toscano en el porticus in summae cavea, las cuales si podrían estar exentas, aunque avanzado el momento en el que se erigiría la posible cripta de Santa Engracia, y en el supuesto de que proviniesen del anfiteatro las columnas referenciadas, nos encontraríamos bien con restos de columnas de orden toscano ${ }^{6}$ (Wilson, 1993) o bien que ya no existiesen debido al desmonte y reutilización de los elementos arquitectónicos, en tiempos aún bajoimperial, para la construcción de las villas que rodeaban al propio núcleo urbano, aunque no podemos aventurarnos en afirmar tal cuestión. Sin embargo queremos hacer un inciso sobre algunos anfiteatros en los que se construyeron en sus arenas estructuras relacionadas con el culto cristiano, pues gracias a ello se mantuvieron los lugares donde los mártires fueron ajusticiados para mantener su memoria (Galve y Blanco, 2001-2002), pudiendo determinar los casos de Tarraco, San Pedro de las Arenas (Metz), San Jacobo de las Arenas (Besançon), San Martín de las Arenas (Nimes), Santa María de las Arenas (Ancona), Santa María de la Arena (Padua), Salona, Durres o Arles, identificándose el término arena como sinónimo de anfiteatro (Sales, 2011; Gurt y Diarte, 2012; Hidalgo, 2012).

5 Los anfiteatros de Pompeya, Mérida y Saintes tenían un perímetro continuo sin arcada en la fachada (Wilson, 1993, p. 440) y por tanto, no se puede incluir entre los anteriormente mencionados.

6 El orden toscano se destaca como un sello particular en la construcción de los anfiteatros (Wilson, 1993, p. 432), mientras que los órdenes dóricos y jónicos estaban ausentes en la mayoría de ellos, excepto en determinados casos en los que se mostraban en fachada los tres órdenes clásicos (dórico, jónico y corintio) por lo que el toscano se utilizaba como ya se ha comentado, en el interior del edificio para el porticus in summae cavea. 

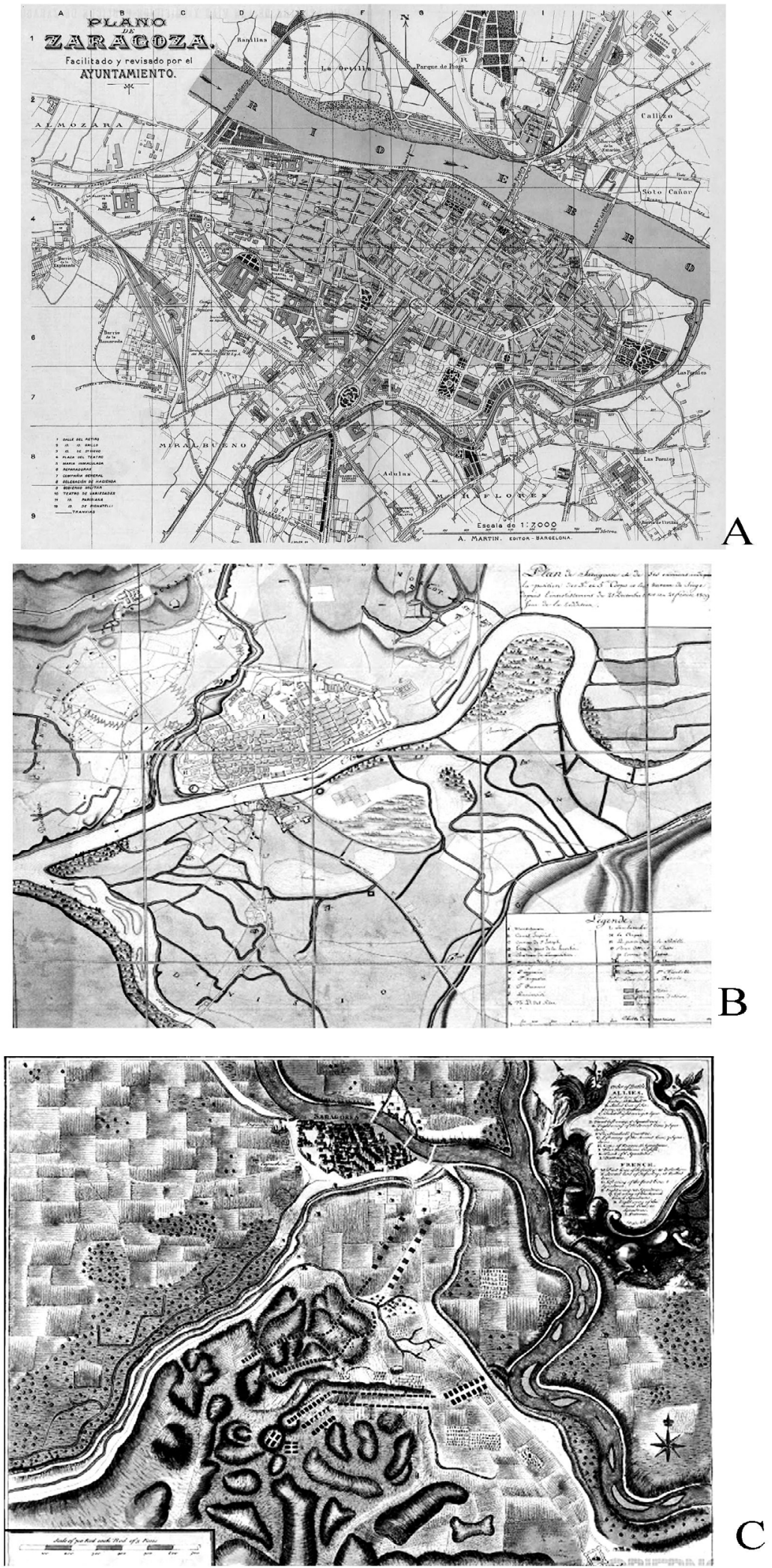

Figura 7: Cauce del río Huerva en distintos planos. 7A.- Plano de A. Martín de 1908; 7B.- Plano de Guillaume Dode de 1808; 7C.- Plano de Tindals de 1710.

Fuente: http://planosymapasdearagon.blogspot.com.es/. 


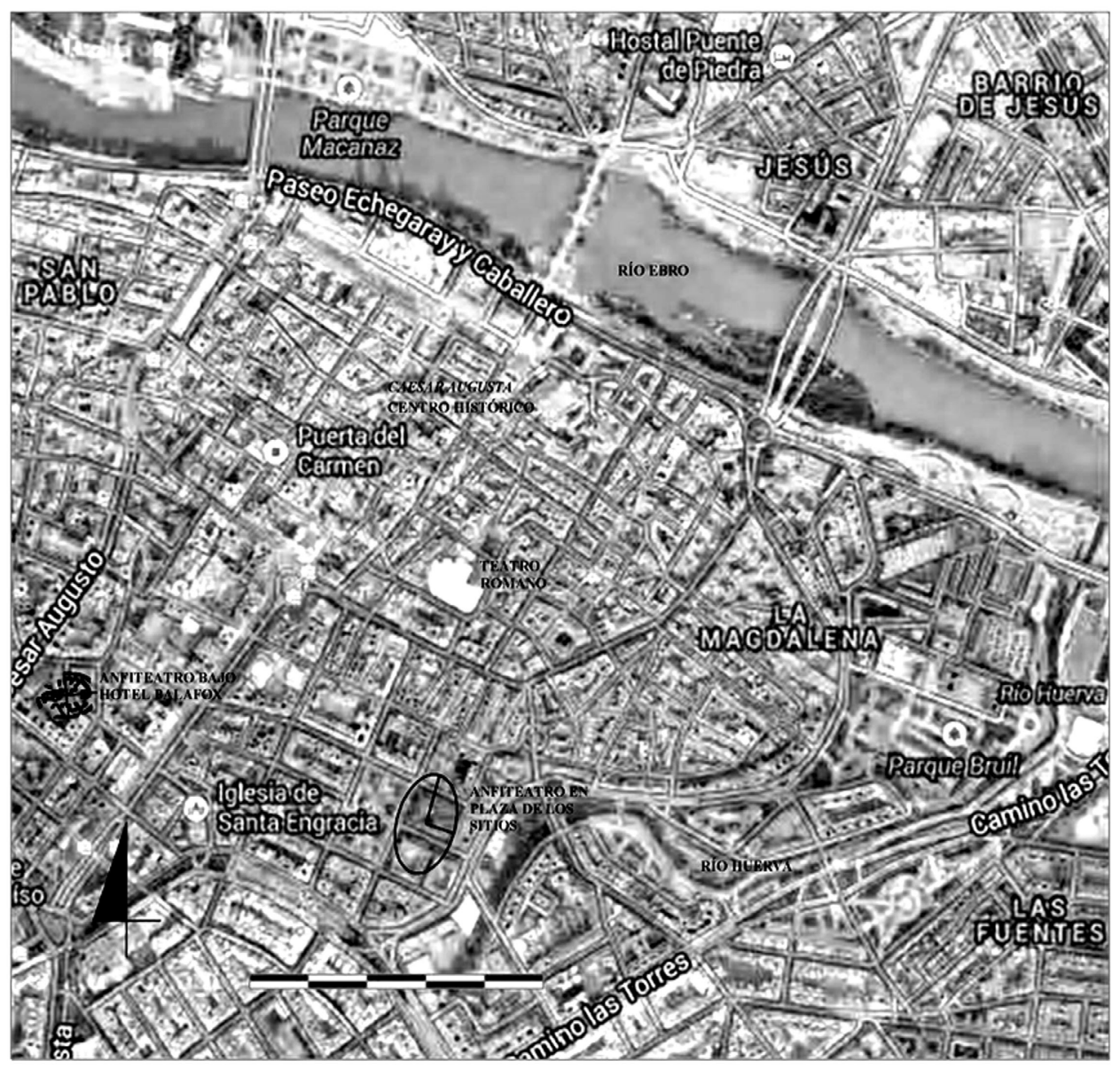

Figura 8: Distintas ubicaciones del supuesto anfiteatro en la Huerta de Santa Engracia, marcado con la flecha, y en la Avenida Cesar Augusto, bajo el Hotel Palafox. Fuente: http://sitar.aragon.es/.

Se quiere relacionar el supuesto edificio anfiteatral con una estructura de culto cristiano (Diarte et al., 2013) tal como ocurre en Tarraco. En cambio, esa ecuación no se da en la totalidad en los edificios anfiteatrales como hemos visto. Fue el martirio del obispo Fructuoso y de sus Diáconos Augurio y Elogio en la arena del anfiteatro de Tarraco en el 259 bajo el reinado de Valeriano (Dupré, 1994), el motivo de que muy posteriormente, en época visigoda, se construyese un martyrium para su culto, edificio que presentaría transformaciones en basílica, iglesia, convento y penal antes de ser abandonado en el siglo XX (Dupré, 1994).

Por un lado tenemos que no en todos los anfiteatros se erigen estos edificios. Por otro lado, se tiene constancia que las estructuras cristianas construidas en los anfiteatros, no tienen por qué señalar que el martirio del santo al que esté consagrado, se diese necesariamente en ese lugar, tomando como ejemplo el propio anfiteatro cordobés al que tanto se alude, quedando demostrado que el Obispo Osio no se encuentra enterrado en el supuesto martyrium, pues se demostró que las estructuras con ábside relacionada con el anfiteatro eran tan sólo contrafuertes adosados al muro del podium (Hidalgo, 2012; Jiménez Hernández, 2015), pero sí se relaciona con el entorno de la martirización de San Acisclo, Santa Victoria y Santa Eugemia (Sánchez, 2006; Hidalgo, 2012).

Por tanto, la basílica más cercana del territorio establecido para la ubicación del supuesto anfiteatro caesaraugustano es la consagrada a Santa Engracia, como hemos comentado, distancia que referencia el plano realizado por los autores (Diarte et al., 2013). Es en este lugar donde se cree que están los restos mortales de la Santa junto a los de sus dieciocho compañeros martirizados bajo el reinado de Daciano (Barraque, 2008), lo que no demuestra en absoluto la utilización de 
la explanada del anfiteatro caesaraugustano como martyrium, ni se puede demostrar que sus elementos arquitectónicos contribuyesen a la edificación de la basílica comentada tan sólo por cercanía.

Se habla también que los mencionados restos podrían pertenecer al Palacio de Galiana (Diarte et al., 2013), ubicado en las riberas del río Huerva. Habría de tenerse en cuenta la toponimia de ello pues como referencia podemos ver Italica en la cual, su historiografía reciente habla de dos lugares con el mismo topónimo, esto es "los Palacios", uno ubicado en la ciudad vieja, en el lugar de las denominadas termas menores, y otro en la ampliación adrianea, en el lugar del Traianeum (Hidalgo, 2003).

Por tanto, los datos con los que se intentan establecer esta hipótesis se basan en el ya comentado trazado semicircular de las plantaciones existentes, en el que se determina un arco donde la unión de sus puntos más alejados es denominada diámetro, con lo que se referiría a un edificio anfiteatral de planta circular, aunque teniendo en cuenta la importancia estratégica y relevancia histórica de la propia colonia caesaraugustana, es difícil entender una forma tan primitiva para la construccion de un anfiteatro de talla media como se presupone. Sin embargo existe contradicción al determinar posteriormente que se trataría de un supuesto eje mayor de $110 \mathrm{~m}$. (Diarte et al., 2013), conformando un edificio de medidas similares a Tarraco con 130 m., o Augusta Emerita con 126 m., sin citar otros anfiteatros de la península como por ejemplo el caso de la propia Italica, o los anfiteatros de Astigi, Carmo, Cartago Noua o Villavieja en Almería, entre otros, de reciente estudio por A. Jimenez en 2015.

\subsection{Acerca de la ubicación extraurbana de los anfiteatros}

Ya hemos visto que se habla de canalizaciones y sistemas de evacuación de aguas y drenaje (Galve, 2004; Beltrán Llorís, 2007-2008) por la zona en la que se intenta establecer el anfiteatro (Diarte et al., 2013), condicionando los resultados del georradar. Se estima, de forma arriesgada, que las cloacas "darían servicio a algunos complejos públicos como las termas de la Plaza de España, espacios urbanos y, por qué no, también a las infraestructuras relacionadas con el posible anfiteatro" (Diarte et al., 2013, p. 125). A pesar de conocer que los anfiteatros contaban con canalizaciones hidráulicas, no se puede mantener esta hipótesis.

Por lo general, la ubicación de los anfiteatros se realizaba extramuros, por el tema de salubridad y control de los animales que participaban en los espectáculos (Diarte et al., 2013) aunque no necesariamente. Por tanto, hemos propuesto una pequeña lista sobre anfiteatros construidos tanto dentro como fuera del pomerium.

De esta forma, encontramos los anfiteatros en el interior del recinto amurallado, en Pompeya (Gros, 1994), el propio anfiteatro Flavio (Gros, 1994), Arlés y Carsulae (Gros, 1994) y Emerita Augusta (Bendala y Durán, 1994) aunque éste último propone discusión sobre su exacta ubicación (Calero, 1994), de la misma forma que encontramos el anfiteatro de Carthago Noua con una ubicación aún por determinar con respecto al núcleo urbano (Pérez, San Martín y Berrocal, 1994), aunque al igual que en Astigi, su planta se localiza bajo la plaza de toros construida entre 1853 y 1854 (Pérez, San Martín y Berrocal, 1994). En cambio, son mayores los ejemplos de anfiteatros construidos en el exterior del recinto amurallado, tales como Tarraco (Dupré, 1994), Emporiae (Sanmartí et al., 1994), Segobriga (Almagro y Almagro-Gorbea, 1994), Italica (Corzo, 1994a), Caparra (Cerrillo, 1994), Conimbriga (Hipólito, 1994), Carmo, Astigi, Gades, Ucubi, Acinipo o Corduba (Corzo, 1994b).

\subsection{Comparaciones estipuladas para el supuesto anfiteatro de Caesar Augusta}

Si se quiere ver Augusta Emerita como una ciudad similar en todas las características a Caesar Augusta, señalando los mismos momentos de construcción, se tendría que valorar al menos esta opción, y una vez se descarte, poder aventurarse en la búsqueda extraurbana de un anfiteatro, en 
el caso de existir (Bendala y Durán, 1994; Calero, 1994; Golvín, 1988; Sales, 2011; Hidalgo, 2008).

También se quiere comprobar la ubicación de los anfiteatros de la Bética, para justificar la existencia de uno en Caesar Augusta, afirmando por ello, la ubicación de todos extramuros y "alineados en la vía Augusta", citando por ello a Corzo en su publicación de 1994 (Diarte et al., 2013, p. 126), que refiere tan sólo a los estudiados en este determinado artículo, los cuales son Corduba, Astigi, Carmo, Hispalis y Gades (Corzo, 1994b). El hecho es que la falta de documentación les induce a errores puesto que el mayor anfiteatro de la Baetica, no citado, como lo es Italica, se encuentra alejado, y por tanto no alineado, de la via Augusta. Su ubicación se podría establecer en la vía de la Plata que lo conduciría hasta Augusta Emerita (Canto, 1999).

Los anfiteatros en la Península lbérica son escasos (Carrasco y Jiménez, 2008; Hidalgo, 2008; Sales, 2011), hecho que estaría ligado al problema de su localización, aunque en nuestra investigación hemos determinado un total de 30 anfiteatros, que distribuimos según las provincias romanas, correspondiendo 12 a la Baetica, 8 a la Lusitania y 10 a la Tarraconensis. Vemos que el mayor volumen de anfiteatros hispanos se centra en la Bética para los datos analizados (Jiménez Hernández, 2015), distribuidos a lo largo de la vía Augusta principalmente, aunque no todos. De todos ellos debemos indicar que algunos se presentan documentados en las fuentes mientras que otros se registran de forma material, por lo que dispondremos para la Baetica de: Acinipo, Astigi, Carmo, Carteia, Italica, Corduba, Gades, Hasta Regia, Malaca, Hispalis (según fuentes documentales), Vcubi y Vrso; para la Lusitania: Aquae Flauia, Balsa, Bobadela, Conimbriga, Emerita Augusta, Bracara Augusta, Ebora y Caparra; y para la Tarraconense: Carthago Noua, Barcino, Emporiom, Segobriga, Sisapo, Lucus Augusti, Vergi, Calagurris, Toletum y Tarraco.

En Hispalis se desconoce la ubicación de su anfiteatro aunque se mantienen dos hipótesis basadas y justificadas en fuentes literarias ${ }^{7}$, y de existir un edificio de espectáculos de este tipo en Hispalis, sería éste el que se alinearía en la via Augusta y no el de Italica. Este ejemplo de Hispalis demuestra que en las ciudades de cierta importancia no tiene por qué disponerse los tres edificios de espectáculos, barajándose las posibilidades de que fuese construido con materiales perecederos, o aprovechándose en este peculiar caso, la existencia del anfiteatro de Italica que por su cercanía y aforo, estaría predispuesto para la acogida de las poblaciones vecinas (González Acuña, 2011).

Por tanto nos encontramos con el dilema de que en caso de existir el anfiteatro de Caesar Augusta pudiese ubicarse intramuros al igual que el caso emeritense, o extramuros, aprovechando el entramado viario que partiría desde la propia colonia caesaraugustana como el caso de Italica. Tal como hemos expuesto anteriormente, podríamos descartar una ubicación interurbana por el hecho de no localizar en ningún estudio ni planos antiguos de los más de cuarenta que hemos consultado, espacio para disponer de un edificio de dimensiones mayores que las de un teatro y por tanto nos inclinamos en que debe de ser buscado en sus alrededores cercanos, aunque teniendo en cuenta que, por el momento, ningún vestigio apoya las teorías que se barajan al respecto.

\subsection{Respecto a la adaptación topográfica}

Si se pretende ver una ubicación extramuros, el área indicada en las proximidades del Huerva no sería la ideal para su establecimiento. Se afirma que Casanova en su plano pudo haber dibujado la alineación de tal forma porque viese los restos del edificio en cuestión (Diarte et al., 2013), hecho imposible de corroborar y de ser cierto, de la misma manera que otros dibujantes vienen realizando desde el siglo XVI, reflejarían los restos tan sólo por asegurarse una mayor antigüedad para la ciudad en cuestión, y así, ubicarla espaciotemporalmente como heredera de la civilización romana, por lo que se representarían los propios restos emergentes, y así podríamos interpretar la

7 Estas fuentes hablan de la atrocidad del menor de los Balbos contra un corredor de subastas en Hispalis, aunque su lectura puede inducir a errores, mientras que la tradición Hagiográfica describe la passio de las santas Justa y Rufina (González Acuña, 2011, pp. 478-479), donde Justa muere en la cárcel y Rufina en el Anfiteatro. 
existencia de alguna estructura que nos induzca a pensar en ello, pero sin embargo, en los planos más antiguos consultados, no se aprecia nada al respecto (Figura 9A-D).

El estudio de Golvín de 1988 nos acerca a las plantas de los anfiteatros que se adaptan a la topografía, por lo que al interpretar los planos debemos tener presente estas disposiciones en las mendidas que encontramos en Carthago Noua (Pérez, San Martín y Berrocal, 1994), Emporiae, el cual se adapta a los desniveles del terreno en una planta alargada (Sanmartí et al., 1994), Segobriga, con una planta tendente a la circularidad (Almagro y Almagro-Gorbea, 1994), Tarraco, excavado en la roca (Dupré, 1994), Emerita Augusta (Bendala y Durán, 1994), o el anfiteatro de Caparra que elige una topografía llana en este caso (Cerrillo, 1994). Al respecto de este último anfiteatro hemos de destacar que su investigador manejó las fotografías aéreas del vuelo de los americanos realizadas en 1956 en el cual apreció unas lindes de olivo irregularmente trazadas, las cuales fueron contrastadas con las fotografías aéreas de 1980 y las mismas lindes de olivo se mostraban ya alineadas correctamente, lo que indica que, de no ser porque detectó los restos del propio anfiteatro in situ, tan sólo con una imagen de olivos alineados o no, no se puede determinar la existencia de ninguna estructura oculta bajo los mismos, pues es evidente la variación que en poco más de veinte años ha sufrido la parte del terreno donde se ubicaba el anfiteatro de Caparra (Cerrillo, 1994). Esta prueba evidente viene a desmontar aún más la teoría propuesta para la localización de un anfiteatro en Caesar Augusta en el lugar donde se pretende ver olivos adaptados a la curvatura que provocarían los cimientos del supuesto anfiteatro.
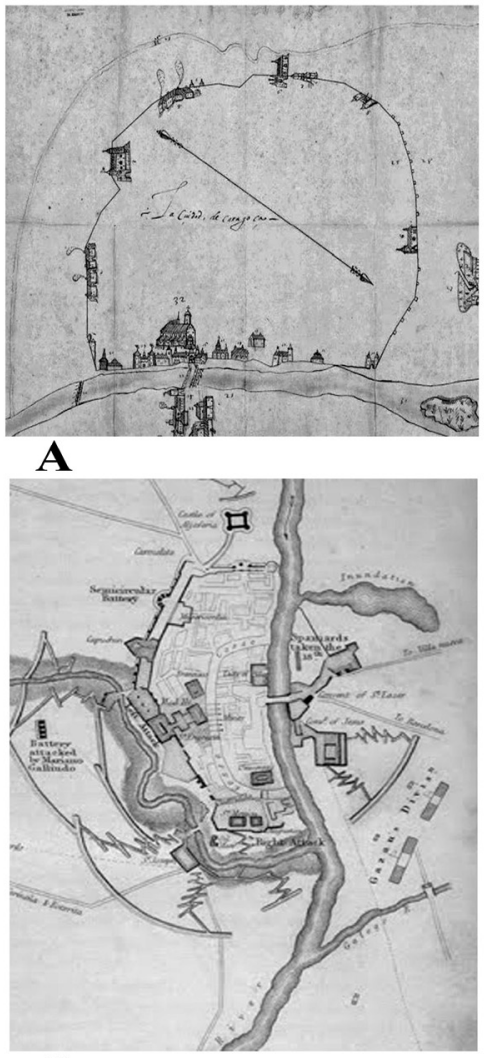

C
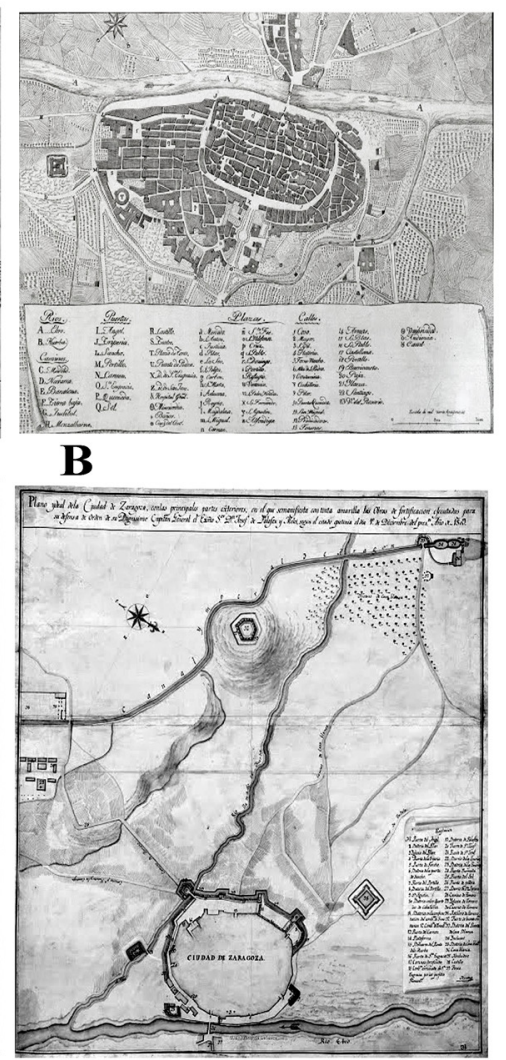

D

Figura 9: Planos antiguos de Zaragoza: 9A.- Idealización de la ciudad realizada en 1592; 9B.- Plano Topográfico de 1830; 9C.- Plano de T\&amp;W Boone realizado en 1829 que recrea los sitios que sufrió la ciudad durante los años 1808 y 1809; 9D.- Plano de Morata de 1809 que idealiza la ciudad de Zaragoza, representando un curso del río Huerva muy cambiado, y ningún edificio elíptico u ovalado en las inmediaciones donde se han supuesto las determinadas hipótesis que estamos aquí refutando. Fuente: http://planosymapasdearagon.blogspot.com.es/. 


\subsection{Resultados de la prospección geofísica}

Respecto a la prospección geofísica realizada, debemos indicar que se parte de varios errores. En primer lugar, parecen aclarar uno de ellos al intentar "evitar la prospección en los sectores donde era previsible la presencia de construcciones antrópicas recientes" (Diarte et al., 2013, p. 127). Se debe tener en cuenta la dificultad que ya de partida ofrece una ciudad superpuesta y con continuidad histórica como lo es Zaragoza. Un segundo problema que se ha debido de tener en cuenta es el tema de las propias canalizaciones o infraestructuras hidráulicas de las que ya hemos hablado. En este punto, debemos poner de ejemplo el estudio de las prospecciones similares que se realizaron en Italica donde nada condicionaba el terreno para interpretar los resultados de las mismas (Hidalgo, 2003; Keay y Rodríguez Hidalgo, 2010).

Se habla de una estructura "que presenta una morfología elíptica alongada N-S con 100-120 m." (Diarte et al., 2013, pp. 128-129), en la que hay que tener en cuenta distintos puntos. En primer lugar, lo anteriormente expuesto sobre el criptopórtico subterráneo de Cercadilla en Córdoba, se puede aplicar a lo detectado, concretándose un simple aterrazamiento del nivel de cota, en función a la morfología dada por el propio cauce del río. En segundo lugar, en la propia figura 6 publicada en la investigación de Diarte y su equipo en 2013 no se aprecia tal "morfología elíptica", sino distintos niveles de profundidad y una interpretación muy subjetiva de los restos sin tener en cuenta las otras figuras presentadas en el propio texto (Diarte et al. 2013). Por tanto, podría corresponder a pozos como parte de las mencionadas infraestructuras hidráulicas. En la misma línea, si se superponen las imágenes 6A de estas investigaciones de Diarte y su equipo con el plano de Casanova y la reconstrucción en las figuras 2 y 4, se observa un eje distinto al de la figura 6B (Diarte et al., 2013), donde se aprecia una supuesta reconstrucción contraria a lo dibujado. Por tanto, no existen suficientes pruebas para afirmar tal hipótesis que bien se arropa en la falta de una excavación arqueológica necesaria (Diarte et al., 2013). En caso de existir restos antrópicos como parece ser el caso, se desconoce la época en la que serían construidos. No se aprecian muros ni alineaciones, ni grosores, tan sólo "anomalías" que justifican que son realizadas por la acción humana, aunque sin ofrecer ninguna alineación de estructuras como en el ejemplo de la prospección italicense (Hidalgo, 2003). Se ha de descartar en este punto, por tanto, la hipótesis de ubicación de un edificio anfiteatral, que en caso de existir en material duradero, dejaría huellas de su cimentación como se detectan en otros casos.

Un paralelo a esta circunstancia es el teatro romano de Singilia Barba (Cortijo de Castillón, al noroeste de Antequera en Málaga), donde gracias a las fuentes literarias existentes desde el siglo $\mathrm{XVI}$, se pudo localizar el teatro (Rodríguez, 2009). Es curioso este aspecto pues en una fotografía de la zona aportada por la doctora Oliva Rodríguez, puede apreciarse que los restos conservados de los extremos de la cavea están bajo alineaciones de olivos, los cuales toman una tendencia lineal no arqueada, y a pesar de la existencia de la cavea o cimentaciones de la misma, no realizan ningún "giro extraño" ni se adapta al terreno como se quiere ver en el plano de Casanova respecto a Caesar Augusta.

\section{Reflexiones finales}

Por último no podemos aventurarnos en afirmar si quiera la existencia de un anfiteatro en Caesar Augusta hasta tener alguna prueba material, epigráfica o literaria que pueda ser contrastada con metodología científica. Con ello no se debe caer en lo estereotipado que establece la existencia de los tres edificios de espectáculos para una ciudad romana (González Acuña, 2011). La mayoría de los anfiteatros aquí consultados mantienen elementos comunes que permiten su determinación, elaboración de planos e incluso su datación cronológica bien mediante restos materiales epigráficos o cerámicos, bien por excavaciones o estratigrafías proporcionadas en las mismas, o bien por la existencia de algunos vestigios que permitan determinar las características constructivas y así el 
periodo al que podrían pertenecer (Almagro y Almagro-Gorbea, 1994; Dupré, 1994; Corzo, 1994a; Corzo, 1994b; Bendala y Durán, 1994; Cerrillo, 1994; Pérez, San Martín y Berrocal, 1994; Sanmartí et al., 1994).

Respecto a la ubicación del anfiteatro caesaraugustano, no se puede aceptar ninguna de las teorías expuestas. La que concierne a la investigación llevada en la Plaza de los Sitios también ha quedado descartada mientras que la que habla sobre una ubicación bajo el Hotel Palafox, parece imposible de aceptar si no se esclarece la estratigrafía realizada para llegar a la elaboración del plano en cuestión. Sería aquí donde se desmontaría esta hipótesis sobre la ubicación bajo el hotel Palafox (Galve 2014), pues el mero hecho de publicarse una supuesta planta de un edificio no implica la existencia del mismo, por lo que sin más datos que especifiquen la superposición de estructuras, no queda otra cosa que negar la ubicación del mismo. Los restos podrían corresponder a infraestructuras hidráulicas, canalizaciones, aterrazamientos o edificios superpuestos amortizando el espacio en época tardía. El hecho de encontrarnos con una supuesta estructura muraria de forma elíptica no debe sorprendernos pues en el Palacio de Cercadilla (Córdoba), las estructuras se disponen en torno a un criptopórtico semicircular con la función de aterrazar o nivelar los distintos cambios de nivel de cota. Este nuevo ejemplo cordobés surgió al Oeste de Corduba como villa Alto Imperial, erigida sobre una necrópolis tras su abandono (Fuerte e Hidalgo, 2005), lugar donde posteriormente se construyó el Palacio de Cercadilla tras profundas transformaciones que consistieron en superar el desnivel en pendiente Norte a Sur, nivelando una gran terraza semicircular (a modo de criptopórtico subterráneo) en torno a la que se conformó el peculiar conjunto (Fuerte e Hidalgo, 2005).

En este punto, el paralelo más cercano lo tenemos nuevamente en Italica donde la estratigrafía llevada a cabo por D. Manuel Pellicer determina una dinámica histórico-cultural que brevemente se resume de la siguiente forma: la existencia de un yacimiento tartésico en el cerro de la Cabeza al norte del anfiteatro en el siglo VIII a. C. se ve relacionado con el afluente del Guadalquivir denominado Madre Vieja, el cual cambia de curso, alejándose del cerro, y el mencionado asentamiento se ve en la obligación de trasladarse (Pellicer, 1998) al actual emplazamiento de Santiponce, donde encontramos el cerro de los Palacios (conocido por el lugar en el que se ubicarán posteriormente las denominadas termas menores de la ciudad vieja romana) y el cerro de San Antonio (el cual se ha comprobado según las últimas investigaciones que parte del mismo fue de recreación artificial (Rodríguez, 2009) por la actividad de los siglos), en el cual se emplaza en sus laderas el posterior teatro romano de la Vetus Vrbs de Italica. En este lugar se formó el asentamiento turdetano entre los siglos IV-III a. C. (Pellicer, 1998), lugar elegido por Escipión para establecer a su contingente itálico. El hecho viene dado que en apenas cuatro siglos, el curso del río cambió, haciendo desaparecer el afluente Madre Vieja y obligando al desplazamiento de la población ubicada estratégicamente en una zona comercial (Rodríguez Gutiérrez y García Fernández, 2016).

Para el caso de Caesar Augusta, no podemos afirmar ningún desplazamiento de población con tanto espacio de diferencia, aunque debemos recordar que la ocupación romana se realizó sobre el núcleo indígena de Salduie (Magallón, 1990; Gómez Pantoja, 1994; Escudero y Galve, 2013; Galve, 2014) si bien habría de tenerse en cuenta el cambio de los cursos de los afluentes del Ebro que influenciaban en los movimientos poblacionales y las alteraciones topográficas que, como hemos visto en nuestro caso, fueron necesarias obras de infraestructuras hidráulicas para evitar inundaciones (Beltrán Llorís, 2007-2008; Galve, 2014).

Un breve apunte para terminar, respecto a los planos consultados, debemos indicar que en su totalidad ascienden a 45, entre los históricos y los actuales, siendo el plano más antiguo de 1592, y los más recientes los propios de los buscadores cartográficos y visualizadores de imágenes aéreas tales como IGN, Google Maps o Cartografía Aragonesa, por citar algunas de los recursos utilizados. En ellos se ha podido comprobar la peculiar e inconfundible planta de Zaragoza, el curso tanto del río Ebro como de su afluente el Huerva que contextualiza parte de esta investigación.

Sin aventurarnos en proponer una hipótesis que carezca de pruebas materiales al respecto para afirmar la existencia de un anfiteatro en Zaragoza respecto a la interpretación de los planos, y para no caer en los mismos errores anteriores, hemos señalado dos planos que deberían ser 
analizados para comenzar a plantearse un nuevo lugar donde buscar el anfiteatro zaragozano, que en el caso de existir, cabe la posibilidad de haberse fosilizado en la urbanística (Escudero y Galve, 2013), reflejada en estos documentos de Francisco Coello con fecha de 1853 (Figura 10A) y de Casañal en 1911 (Figura 10B), como se planteó para los casos de Barcelona, Lucca o Florencia (Sales, 2011).
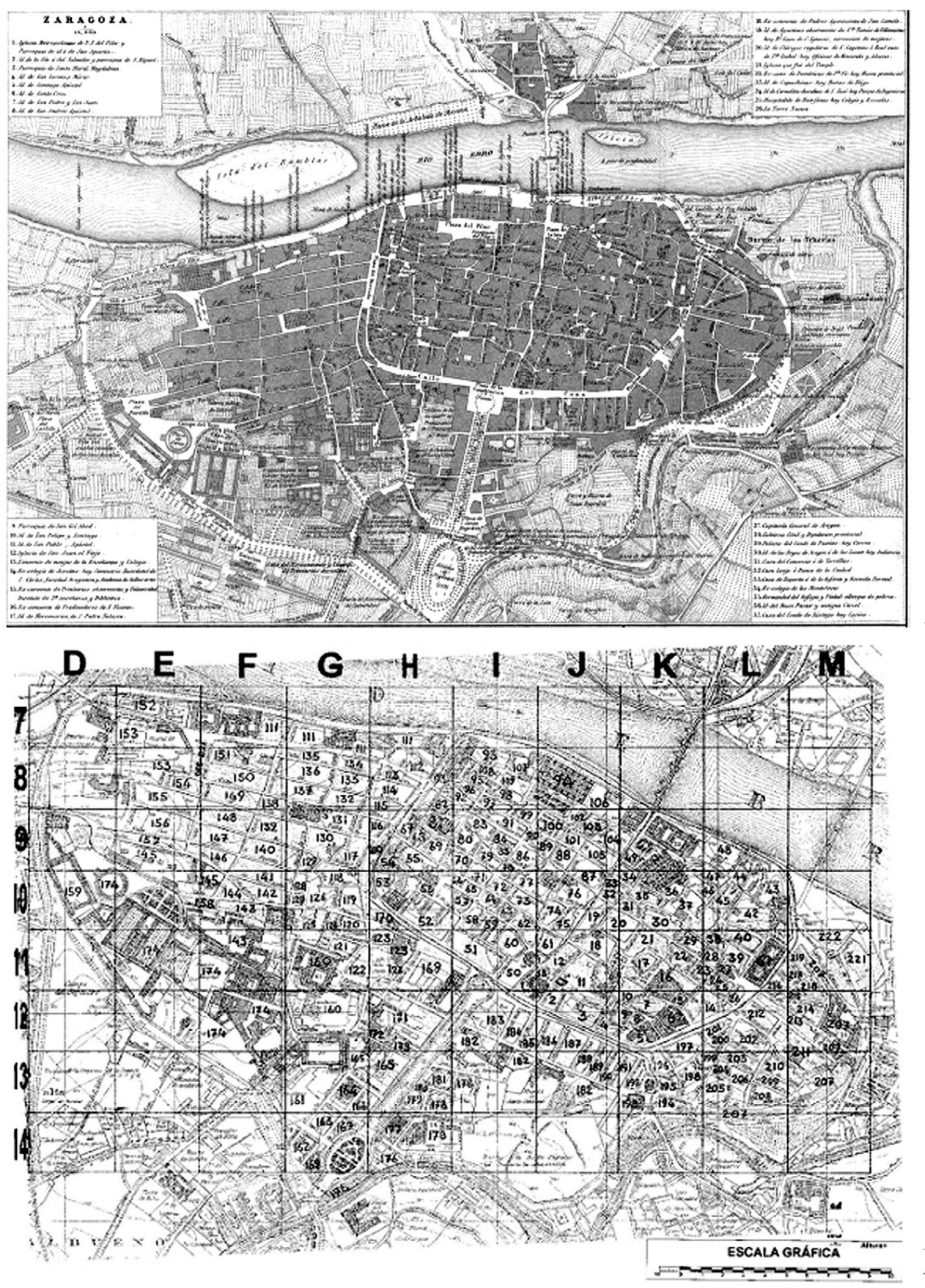

Figura 10: 10A.- Plano de F. Coello de 1853. 10B.- Plano basado en Casañal y parcelado enmanzanas y casas. Fuente: http://planosymapasdearagon.blogspot.com.es/. 


\section{Bibliografía}

Almagro, A. y Almagro Gorbea, M. (1994). El anfiteatro de Segobriga. En Álvarez Martínez, J. M. y Enríquez Navascués, J. J. (coords.). Bimilenario del Anfiteatro Romano de Mérida. Coloquio Internacional el Anfiteatro en la Hispania Romana (Mérida, 26-28 de noviembre de 1992), (pp. 139-176). Mérida: Junta de Extremadura. Consejería de Cultura y Patrimonio.

Andréu Pintado, J. (2003). Incidencia de la municipalización flavia en el Conventus Caesaraugustanus. Saldvie, 3, 163-185.

Barraqué, J. P. (2008). Entre religión real y religión urbana. La España Medieval, 31, 249-274.

Beltrán Llorís, F. (2007-2008). Marcas legionarias de la VI Victrix y la X Gemina en el Foro de Caesaraugusta. Veleia, 24-25, 1069-1079.

Beltrán Llorís, F. y Velaza Frías, J. (2013). El límite occidental del Convento Jurídico Caesaraugustano. Cuadernos de Arqueología, 21, 51-71.

Beltrán Llorís, M. (2007-2008). Un triclinio romano en el Museo de Zaragoza. Veleia, 24-25, 11131121.

Beltrán Llorís, M. (2004). Museo de Zaragoza. Memoria del año 2004. Museo de Zaragoza, Boletín, $18,455-457$.

Beltrán Llorís, M. (1993). El teatro de Caesaraugusta. Estado actual de conocimiento. Teatros romanos de Hispania. Cuadernos de Arquitectura Romana, 2, 93-118.

Beltrán Llorís, M., Mostalac Carrillo, A. y Paz Peralta, J. A. (2009). Caesaraugusta. La casa de los hispanorromanos. Zaragoza: Gobierno de Aragón, departamento de Educación, Cultura y Deporte.

Beltrán Martínez, A. (1976). Symposium de ciudades augusteas. Zaragoza: Librería General S.A.

Bendala Galán, M. y Durán Cabello, R. M. (1994). El anfiteatro de Augusta Emerita: rasgos arquitectónicos y problemática urbanística y cronología. En Álvarez Martínez, J. M. y Enríquez Navascués, J. J. (coords.). Bimilenario del Anfiteatro Romano de Mérida. Coloquio Internacional el Anfiteatro en la Hispania Romana (Mérida, 26-28 de noviembre de 1992), (pp. 247-264). Mérida: Junta de Extremadura. Consejería de Cultura y Patrimonio.

Blázquez Martínez, J. M. (1994). Posibles precedentes prerromanos de los combates de gladiadores romanos en la Península Ibérica. En J. M. Álvarez Martínez y J. J. Enríquez Navascués (coords.). Bimilenario del anfiteatro Romano de Mérida. Coloquio Internacional el anfiteatro en la Hispania Romana, Mérida, 26-28 de noviembre de 1992. (pp. 31-44). Mérida: Junta de Extremadura.

Cabrero Piquero, J. y Cordente Vaquero, F. (2011). Los oficios de la diversión en Roma. Espacio, tiempo y forma. Serie II: Historia Antigua, 24, 363-379.

Calero Carretero, J. A. (1994). La planta del anfiteatro romano de Mérida. En Álvarez Martínez, J. M. y Enríquez Navascués, J. J. (coords.). Bimilenario del Anfiteatro Romano de Mérida. Coloquio Internacional el Anfiteatro en la Hispania Romana (Mérida, 26-28 de noviembre de 1992), (pp. 301-310). Mérida: Junta de Extremadura. Consejería de Cultura y Patrimonio.

Canto, A. (1999). La vetus urbs de Italica, quince años después. La planta hipodámica de D. Demetrio de los Ríos y otras novedades. CUPAUAM , 25.2, 145-191.

Carrasco Gómez, I. y Jiménez Hernández, A. (2008). A cerca de los edificios de espectáculos en Colonia Augusta Firma Astigi (Écija, Sevilla). Romula, 7, 7-52.

Ceballos Hornero, A. (2007a). Geografía y cronología de los ludi en la Hispania romana. Caesaraugusta, 78, 437-454.

Ceballos Hornero, A. (2007b). El coste de los espectáculos gladiatorios en las ciudades del occidente romano. AEspA, 80, 107-118.

Ceballos Hornero, A. y Ceballos Hornero, D. (2009). Competiciones de lucha en la Hispania antigua. Pyrenae, 40, 57-79.

Ceballos Hornero, A. y Ceballos Honero, D. (2003). Los espectáculos del anfiteatro en Hispania. Iberia, 6, 57-70. 
Cebolla Berlánga, J. L., Domínguez Arranz, A. y Ruiz Ruiz, F. J. (2004). La excavación arqueológica del solar de la Plaza de las Tenerías, no 3-5 (Zaragoza). Saldvie, 4, 463-472.

Cerrillo Martín de Cáceres, E. (1994). El anfiteatro de Caparra. En Álvarez Martínez, J. M. y Enríquez Navascués, J. J. (coords.). Bimilenario del Anfiteatro Romano de Mérida. Coloquio Internacional el Anfiteatro en la Hispania Romana (Mérida, 26-28 de noviembre de 1992), (pp. 311-326). Mérida: Junta de Extremadura. Consejería de Cultura y Patrimonio.

Conde Moraguez, L. (2013). Hipótesis sobre la posible identificación del anfiteatro de Barcino. Pyrenae, 44, 47-68.

Corzo Sánchez, R. (1994a). El anfiteatro de Italica. En Álvarez Martínez, J. M. y Enríquez Navascués, J. J. (coords.). Bimilenario del Anfiteatro Romano de Mérida. Coloquio Internacional el Anfiteatro en la Hispania Romana (Mérida, 26-28 de noviembre de 1992), (pp. 187-212). Mérida: Junta de Extremadura. Consejería de Cultura y Patrimonio.

Corzo Sánchez, R. (1994b). Notas sobre el anfiteatro de Carmona y otros anfiteatros de la Bética. En Álvarez Martínez, J. M. y Enríquez Navascués, J. J. (coords.). Bimilenario del Anfiteatro Romano de Mérida. Coloquio Internacional el Anfiteatro en la Hispania Romana (Mérida, 26-28 de noviembre de 1992), (pp. 239-246). Mérida: Junta de Extremadura. Consejería de Cultura y Patrimonio.

Diarte Blasco, P. (2014). Un camino sin retorno: la desarticulación de la ciudad clásica en laAntigüedad Tardía (ss. IV-V d. C.). En Martín-Bueno, M. y Sáenz Preciado, J. C. (eds.). Modelo edilicios y prototipos en la monumentalización de las cudades de Hispania. Monografías Arqueológicas, 49, Zaragoza, 97-106.

Diarte Blasco, P., Martín López, A., Sebastián López, M., Pueyo Anchuela, O., Casas Sáinz, A. M. y Pocoví, J. (2013). Una nueva hipótesis sobre la localización del anfiteatro de Caesaraugusta (Zaragoza, España). Pyrenae, 44, 117-134.

Dupré i Raventos, X. (1994). El anfiteatro de Tarraco. En Álvarez Martínez, J. M. y Enríquez Navascués, J. J. (coords.). Bimilenario del Anfiteatro Romano de Mérida. Coloquio Internacional el Anfiteatro en la Hispania Romana (Mérida, 26-28 de noviembre de 1992), (pp. 79-90). Mérida: Junta de Extremadura. Consejería de Cultura y Patrimonio.

Escudero, F. A. y Galve, P. (coords.) (2013). Las cloacas de Caesaraugusta y elementos de urbanismo y topografía de la ciudad antigua. Zaragoza: Institución Fernando el Católico.

Fabié, A. M. (1892). El nuevo bronce de Italica. Boletín de la Real Academia de la Historia, 21, 385397.

Fatas Cabeza, G. (2013). Cicerón y el buen gobierno en el primer cinquecento zaragozano. En Beltrán, J. A., Encuentra, A., Fontana, G., Magallón, A. I. y Marina, R. M. (eds.). Otivm cvm dignitate. Estudios en homenaje al profesor José Javier Iso Echegoyen. Zaragoza: Universidad de Zaragoza, 653-664.

Fatas Cabeza, G. (1998). La historia militar de Aragón en la Edad Antigua: el Ebro y el Pirineo. Militaria, 12, 15-30.

Fuertes Santos, M. C. e Hidalgo Prieto, R. (2005). Guía del yacimiento arqueológico de Cercadilla. Sevilla: Junta de Andalucía.

Galve, P. (2014). Zaragoza antigua (Salduie y Caesaraugusta): actualidad de la investigación arqueológica. En Martín-Bueno, M. y Sáenz Preciado, J. C. (eds.). Modelo edilicios y prototipos en la monumentalización de las cudades de Hispania. Monografías Arqueológicas, 49, Zaragoza, 43-55.

Galve, P. (2004). Una ciudad consolidada: Caesaraugusta a mediados del siglo I. En Álvarez Gracia, A. y Marcelo Calvín, J. R. (coords.): Zaragoza. Visiones de una ciudad. Zaragoza, 13-33.

Galve, P. y Blanco, A. (2001-2002). Nuevos datos para la arqueología funeraria de Caesaraugusta: las tumbas paleocristianas de la calle Mosén Pedro Dosset (Vial) (Zaragoza). Saldvie, 2, 409414.

García García, S., Casteels Vela, R. y Erice Lacabe, R. (2007). La ruta de Caesaraugusta: un itinerario por la ciudad romana de Zaragoza. Mus-A, 8, 117-120. 
García Naranjo, J. (1951). El anfiteatro romano de Italica. Conferencia de divulgación arqueológica. Sevilla.

García y Bellido, A. (1961-1962). Las colonias romanas de Valentia, Carthago Nova, Libisosa e llici. Aportaciones al estudio del proceso de romanización del S. E. de la Península. En Homenaje al Profesor Cayetano de Mergelina. Murcia, 367-372.

Garrido Moreno, J. (2005). El anfiteatro: una oscura imagen de la antigua Roma. Berceo, 149, 153178.

Garriguet, J. A. (2010). El Anfiteatro de Colonia Patricia Corduba en el marco de la ideología imperial. En Vaquerizo Gil, D. y Ruiz Osuna, A. (2010). In amphitheatro. Munera et funus. Análisis arqueológico del anfiteatro romano de Córdoba y su entorno urbano (ss. I-XIII d. C.) (pp. 466480). Córdoba.

Gascón Lascas, A. P. (2009). A propósito del estudio de un basurero doméstico romano de época altoimperial en Caesaraugusta: el caso del vertedero de C/Preciadores, 24-26. Saldvie, 9, 217-228.

Golvín, J. C. (1988). L`Amphitheatre Romain. París: Archeologie Nouvelle.

Gómez Pantoja, J. (1994). Germánico y Caesaraugusta. Polis, 6, 169-202.

Gómez Pantoja, J. (1976). La ciudad romana de Calahorra. En Beltrán, A. (ed.). Symposion de ciudades augusteas (Zaragoza, 29 de noviembre al 2 de diciembre de 1976), vol. II (pp. 185190). Zaragoza.

Gómez, C., Parruca, P. y Ros, P. (2009). Las casas romanas en Aragón. Zaragoza: Diputación General de Aragón, departamento de Educación, Ciencia y Deporte.

González Acuña, D. (2011). Forma Vrbis Hispalensis. El urbanismo de la ciudad romana de Hispalis a través de los testimonios arqueológicos. Sevilla.

Gros, P. (1994). L'amphitheâtre dans la ville. Politique "culturelle" et urbanisme aux deux premiers siècles de l’Empire. En Álvarez Martínez, J. M. y Enríquez Navascués, J. J. (coords.). Bimilenario del Anfiteatro Romano de Mérida. Coloquio Internacional el Anfiteatro en la Hispania Romana (Mérida, 26-28 de noviembre de 1992), (pp. 13-30). Mérida: Junta de Extremadura. Consejería de Cultura y Patrimonio.

Gros, P. y Torelli, M. (2007). Storia dell urbanistica. Il mondo romano. Bari, Roma.

Gurt Esparraguera, J. M. y Diarte Blasco, P. (2012): "La Basílica de Santa Leocadia y el final de uso del circo romano de Toledo: una nueva interpretación", Zephyrus, 69, 149-163.

Hipólito Correia, V. (1994). O anfiteatro de Conimbriga. En Álvarez Martínez, J. M. y Enríquez Navascués, J. J. (coords.). Bimilenario del Anfiteatro Romano de Mérida. Coloquio Internacional el Anfiteatro en la Hispania Romana (Mérida, 26-28 de noviembre de 1992), (pp. 345-348). Mérida: Junta de Extremadura. Consejería de Cultura y Patrimonio.

Hernández Hervás, E., López Piñol, M. y Pascual Buyé, I. (1995). La implantación del circo en el área suburbana de Saguntum. Saguntum, 29, 221-230.

Hernández Vera, J. A. y Núñez Marcén, J. (2000). La ordenación del espacio de la Zaragoza prerromana y romana. Saldvie, 1, 181-202.

Hernández Vera, J. A. y Núñez Marcén, J.. (1997). Un nuevo capitel corintio procedente de Caesaraugusta. Zephyrus, 50, 289-303.

Hidalgo Prieto, R. (2012). Sobre el supuesto centro de culto cristiano del Anfiteatro de Córdoba. Habis, 43, 249-274.

Hidalgo Prieto, R. (2008). Anfiteatros. En León Alonso, P. (coord.). Arte romano de la Bética. Arquitectura y Urbanismo. Sevilla, 223-232.

Hidalgo Prieto, R. (2003). En torno a la imagen urbana de Italica. Romula, 2, 89-126.

Hidalgo Prieto, R. y Márquez Moreno, C. (2010). Arquitectura oficial. En Caballos Rufino, A. (coord.). Italica-Santiponce: Municipium y Colonia Aelia Augusta Italicensium. Sevilla, 57-66.

luste Arruga, M. N. (1993). Nuevos yacimientos en el trazado de la vía romana CaesaraugustaOsca. Bolskan, 10, 187-222.

Jiménez Hernández, A. (2015). Anfiteatros romanos en la Bética: reflexiones sobre su geometría, 
diseño y traza. AEspA, 88, 127-148.

Keay, S. y Rodríguez Hidalgo, J. M. (2010). Topografía y evolución urbana. En Caballos Rufino, A. (ed.). Italica-Santiponce. Municipium y Colonia Aelia Augusta Italicensium. Sevilla, 43-55.

Magallón Botaya, M. A. (1990). Organización de la red viaria romana en el valle medio del Ebro. En Beltrán, A. (coord.). Simposio sobre la red viaria en la Hispania romana (pp. 301-316). Zaragoza: Institución Fernando el Católico.

Martín Escorza, C. (2008). Dimensiones y orientaciones de anfiteatros y Circos romanos en el Imperio romano. Kalakorikos, 13, 185-193.

Melchor Gil, E. (1994). Consideraciones acerca del origen, motivación y evolución de las conductas evergéticas en Hispania romana. Studia Historica, 12, 61-68.

Naselli Macera, D. (2010). Carpóforo. Un bestiarius para el anfiteatro. Huellas de la Historia, 8, 1-16.

Ortiz Palomar, E. y Paz Peralta, J. A. (2009). Vidrios decorados inéditos de Caesar Augusta y Asturica Augusta (Hispania). Reveladora presencia de distintivos militares. Saldvie, 9, 179-216.

Pellicer Catalán, M. (1998). Los cortes estratigráficos de Italica y su contribución al estudio de la dinámica histórico-cultural del yacimiento. Boletín de Bellas Artes, 26, 143-186.

Pérez Ballester, J., San Martín Moro, P. A. y Berrocal Caparrós, C. (1994). El anfiteatro romano de Cartagena (1967-1992). En Álvarez Martínez, J. M. y Enríquez Navascués, J. J. (coords.). Bimilenario del Anfiteatro Romano de Mérida. Coloquio Internacional el Anfiteatro en la Hispania Romana (Mérida, 26-28 de noviembre de 1992), (pp. 91-118). Mérida: Junta de Extremadura. Consejería de Cultura y Patrimonio.

Pérez Lambán, F., Fanlo Loras, J. y Picazo Millán, J. V. (2010). El poblamiento antiguo en el valle del río Huerva. Resultados de las campañas de prospección de 2007-2009. Saldvie, 10, 285-315.

Rodríguez Gutiérrez, O. (2009). Algunas reflexiones en torno a los teatros romanos de la Bética. En Bernal, D. y Arevalo, A. (eds.) (2009). El Theatrum Balbi de Gades. Actas del Seminario el Teatro romano de Gades. Una mirada al futuro (Cádiz, 18-19 noviembre de 2009). (pp. 335371). Cádiz.

Rodríguez Gutiérrez, O y García Fernández, F. J. (2016). Itálica: la fundación de Publio Cornelio Escipión Africano en el corazón de la Hispania púnica. En Bendala Galán, M. (coord.). Los Escipiones. Roma conquista Hispania. Alcalá de Henares, 5-23.

Sales Carbonell, J. (2011). Santa María de las Arenas, Santa María del Mar y el anfiteatro romano de Barcelona. Revista d arqueología de ponent, 21, 61-74.

Sánchez Velasco, J. (2006). Hipótesis de ubicación de un anfiteatro extramuros en Colonia Patricia Corduba y localización de la sede del concilio provincial de la Betica. SPAL, 15, 313-338.

Sanmartí Greco, E., Aquilué, X., Castanyer, P., Santos, M. y Tremoleda, J. (1994). El anfiteatro de Emporiae. En Álvarez Martínez, J. M. y Enríquez Navascués, J. J. (coords.). Bimilenario del Anfiteatro Romano de Mérida. Coloquio Internacional el Anfiteatro en la Hispania Romana (Mérida, 26-28 de noviembre de 1992), (pp. 119-138). Mérida: Junta de Extremadura. Consejería de Cultura y Patrimonio.

Santos Yanguas, N. (2008). La nueva gladiatura cristiana en el marco de la gladiatura romana. Hispania Antiqua, 32, 183-212.

Sevilla Conde, A. (2009). El impacto de la romanización en los territorios de la provincia Tarraconensis a través de la arqueología funeraria. Una primera aproximación. Saldvie, 9, 229-247.

Vaquerizo, D y Murillo, J. F. (eds.) (2011). El Anfiteatro romano de Córdoba y su entorno urbano. Análisis Arqueológico (ss. I-XII d. C.). Córdoba.

Wilson Jones, M. (1993). Designin Amphitheatres. Römische Mitteilungen, 100, 391-441. 


\section{Recursos Web}

http://aragonromano.blogspot.com.es/2011/04/el-anfiteatro-de-caesaraugusta-bajo-el.html (consultado el 16 de Noviembre de 2013)

http://catedu.es/aragonromano/anfiteat.htm (consultado el 14 de noviembre de 2013).

http://commons.wikimedia.org/wiki/File:Plano topogr\%C3\%A1fico de la ciudad de Zaragoza.jpg (Plano antiguo sin fecha; alineación de los olivos) (consultado el 16 de Noviembre de 2013)

http://commosn.wikimedia.org/wiki/File:Zaragoza - Primer Sitio.jpg (plano de 1808) (consultado el 16 de noviembre de 2013)

http://ecoter.files.wordpress.com/2011/03/m-247.jpg (plano 1878) (consultado el 16 de noviembre de 2013)

http://es.wikipedia.org/wiki/Sitios de Zaragoza (consultado el 16 de noviembre de 2013)

https://maps.google.es/maps?q=Zaragoza\&ie=UTF-8\&hq=\&hnear=Oxd5914... (consultado el 16 de noviembre de 2013)

http://planosymapasdearagon.blogspot.com.es/ (consultado el 10 de febrero de 2014).

http://sitar.aragon.es/visor/\# (consultado el 16 de noviembre de 2013)

http://sitar.aragon.es/cartoteca/\# (consultado el 16 de noviembre de 2013)

http://sitar.aragon.es/atlas-cartografia.htm?GG=3\&LL=Z\&PP=50 (consultado el 16 de noviembre de 2013)

http://www.ign.es/PNOA/enlaces relacionados historico.html (consultado el 16 de noviembre de 2013)

http://www.manfredclauss.de/es/ (consultado el 15 de noviembre de 2013)

http://www.pyrenae.com/home/index.php?option=com k2\&view=item\&id=155:unanueva-hipotesis-sobre-la-localizacion-del-anfiteatro-de-caesaraugusta-zaragozaespana\&ltemid=251\&lang=es (consultado el 16 de noviembre de 2013)

http://www.spanisharts.com/arquitectura/roma espectaculos.html (consultado el 26 de diciembre de 2013).

http://www.spanisharts.com/arquitectura/imagenes/roma/ciudad cartagena.html (consultado el 26 de diciembre de 2013).

http://www2.ign.es/iberpix/visoriberpix/visorign.html (consultado el 16 de noviembre de 2013).

\section{Fuentes}

Estrabón. Geografía de Iberia. Madrid: Alianza. 2009. [Traducción de Javier Gómez Espelosín]. Madrid: Alianza.

Plinio el Viejo (1998). Historia Natural. Libros III-IV. Madrid: Gredos. 1998. [Traducción y notas de Luis Alfonso Hernández y Francisco Manzanero]. 


\section{Panta Rei}

PANTA REI es una revista digital de investigación orientada a la Historia y otras ciencias afines. Su principal objetivo es la transmisión del conocimiento científico, dando una oportunidad también a los jóvenes investigadores que quieren abrirse camino en el estudio de las ciencias humanas y sociales. Se compone de estudios originales relacionados con la disciplina histórica así como su didáctica y difusión. Las diferentes secciones que componen la revista son: artículos de investigación, entrevistas a profesionales, recensiones de monografías de actualidad y crónicas de congresos o eventos científicos relevantes.

Todos los artículos publicados son objeto de un proceso de revisión a cargo de un mínimo de dos evaluadores, que se consideran expertos en el ámbito temático del artículo propuesto. Nuestro deseo es poder ofrecer unos contenidos rigurosos, de calidad y de interés.

EI CEPOAT (Centro de Estudios del Próximo Oriente y la Antigüedad Tardía de la Universidad de Murcia) es la institución encargada de la coordinación y gestión de la revista, desde donde anualmente se lanzará la convocatoria para aquellos que estén interesados en publicar sus trabajos, siempre relacionados con la Historia, Arqueología, Historia del Arte, Didáctica de las Ciencias Sociales, etc.

PANTA REI is a digital journal focused on History and other sciences related to it. Its main objective is the transmission of scientific knowledge by giving also an opportunity to young researchers who want to make their way in the study of human and social sciences. It is composed by original studies related to History, as well as its didactics and promotion. The different sections of this journal are: research articles, interviews to professionals, recensions on monographs about current issues and reports about congresses or relevant scientific events.

All the articles published are subject to a revision process carried out by a minimum of two reviewers who are considered to be experts in the field of the article proposed. Our wish is to offer rigorous contents with quality and being of interest to the reader.

CEPOAT (Centre of Studies of the Middle East and Late Antiquity of the University of Murcia) is the institution in charge of the coordination and management of this journal. This is the centre from where the call for papers will be launched for all the people interested in publishing their papers, always related to History, Archeology, Art History, Didactics of the Social Sciences, etc. 


\section{Normas de Publicación}

El autor se compromete a enviar trabajos originales, que no se encuentren publicados en otras revistas ni en otros idiomas. Así mismo, el mismo artículo no podrá ser presentado en otras revistas mientras dure el proceso de evaluación.

\section{Envío y presentación de originales}

Los artículos se enviarán exclusivamente a través del correo electrónico a la dirección pantarei@um.es. Los textos serán enviados en formato DOC y las imágenes en formato JPEG o TIFF, y con un tamaño mínimo de 2000 px. Éstas no aparecerán incorporadas en el texto, sino enviadas en archivo aparte y correctamente numeradas según su posición en el texto. Junto al trabajo, se rellenará y enviará un documento aparte en el que se especifiquen los datos del autor siguiendo el modelo disponible en la página Web de la revista.

Para la redacción de los trabajos se tendrá en cuenta el Manual de la American Psychological Association, en su sexta edición. La extensión máxima de los trabajos será de 30 páginas. La tipografía será Arial 11, con interlineado sencillo y sin espacio alguno entre párrafos. El texto deberá ir justificado a ambos márgenes y sin sangría en los primeros párrafos. Los márgenes serán de $2,50 \mathrm{~cm}$. En los casos en los que fuera necesario incorporar notas, éstas irán a pie de página, enumeradas consecutivamente, con tipografía Arial 10, interlineado sencillo y justificadas a ambos márgenes.

Una información más detallada se encuentra disponible en la página http://www.um.es/cepoat/ pantarei.

\section{Proceso de valoración y evaluación}

Una vez recibidos los trabajos, la Revista realizará una primera valoración. Si el trabajo enviado se ajusta a las normas de presentación propuestas, la temática es coincidente con la línea editorial de la revista y posee la calidad científica necesaria, será remitido al consejo asesor para una primera evaluación. Si no es así en este primer paso se puede rechazar directamente los documentos que incumplan claramente la línea editorial.

Será el Consejo Asesor quien indique a la revista la originalidad, relevancia, estructura, redacción, aparato bibliográfico, etc. del trabajo enviado y, para ello, se designará a dos revisores expertos externos que evaluarán cada uno de los trabajos, que pueden formar parte (o no) de este Consejo Asesor. La selección de los revisores se ajustará a la temática y características metodológicas del trabajo. El nombre y filiación de los autores serán eliminados del trabajo para su revisión, así como los revisores actuarán de manera anónima y confidencial.

Los revisores deberán rellenar un informe de evaluación que centrará su atención en aspectos tales como características formales, originalidad y novedad de los trabajos, relevancia de las propuestas y los resultados, calidad metodológica y validez científica.

Una vez terminado el proceso se decidirá la aceptación o no de los mismos y su publicación en el número que sea pertinente, así como las modificaciones susceptibles de ser realizadas para su final publicación. Dicha notificación se enviará únicamente por correo electrónico, en un plazo máximo de seis meses. 


\section{Publishing rules}

The author is committed to submit original papers not having been published in other reviews or in other languages. In this way, it is not allowed for the same paper to be presented in other reviews during the evaluation process.

\section{Submission and presentation of originals}

The articles will be exclusively submitted by email to pantarei@um.es. The texts will be submitted in DOC format and the images in JPEG or TIFF format, and with a minimum size of 2000 px. Images will not be integrated in the text but sent in another file and properly numbered according to their position in the text. Attached to the paper, a document will be filled out and sent where the author's data will be specified following the model available on the website.

The sixth edition of the Manual of the American Psychological Association will be taken into account for the writing of the papers. The length of the papers must not exceed 30 pages. Typography will be Arial 11 , with simple line spacing and no space between paragraphs. The text must be justified on both margins without indentation in the first paragraphs. Margins size will be $2.50 \mathrm{~cm}$. Where it could be necessary the incorporation of notes, they will be at the bottom of the page, consecutively numbered with typography Arial 10, simple line spacing and justified on both margins.

More detailed information is available on the website: http://www.um.es/cepoat/pantarei.

\section{Examination and assessment process}

The Journal will submit the papers to a first examination once received. If the paper follows the presentation guidelines, the subject agrees with the editorial line of this journal, and possess the scientific quality required, it will be sent to the advisory council for a first assessment. If not, the documents which clearly fail to complete the editorial line may be rejected straightaway in this first step.

The Advisory Council will indicate the originality, relevance, structure, writing, bibliography, etc. of the text to the journal; for this purpose, two outside experts will be designated to review the papers; these experts can be (or not) part of this Advisory Council. The selection of the experts will adjust to the subject and methodological characteristics of the paper. Name and affiliation of the author will be eliminated from the text for its review, in this way experts will act anonymously and confidentially.

The experts will fill out an assessment report which will focus on aspects such as formal characteristics, originality and novelty of the papers, relevance and results of the proposal, methodological quality and scientific validity.

Once the process is finished, the acceptance or not of the papers and its publication in the corresponding edition will be decided, as well as the modifications that may be done for its final publication. This notification will be sent by email within 6 months maximum. 


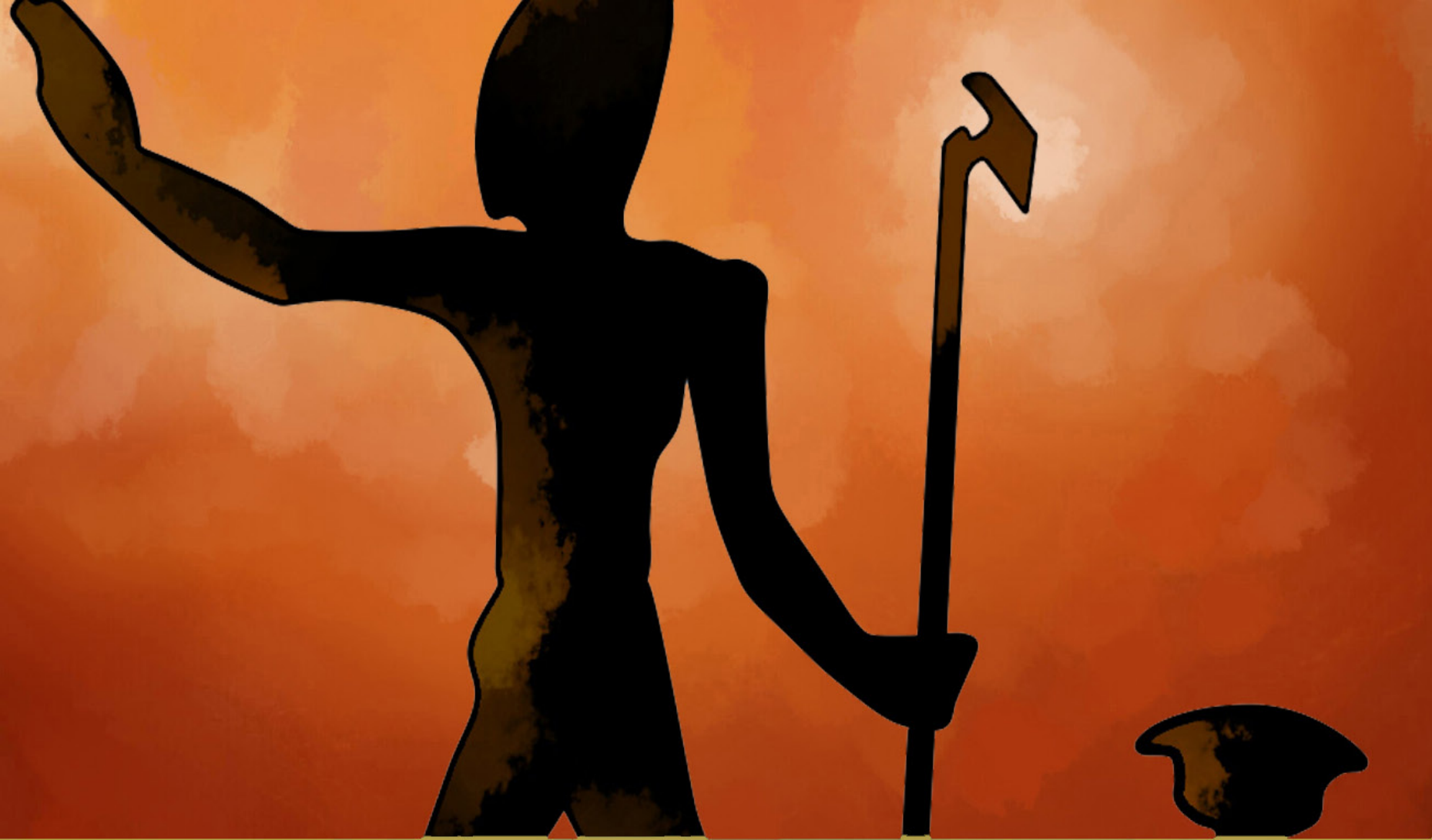

cepo t

UNIVERSIDAD DE MURCIA

centro de estudios del

próximo oriente y la

antigüedad tardía 